\title{
ESTUDO CLÍNICO DA MENSURAÇÃO DA GIBOSIDADE E SUAS CORRELAÇÕES COM MEDIDAS RADIOLÓGICAS NA ESCOLIOSE IDIOPÁTICA
}

Dalva Minonroze Albuquerque Ferreira

Dissertação de Mestrado apresentada à Escola de Engenharia de São Carlos, Faculdade de Medicina de Ribeirão Preto e Instituto de Química de São Carlos da Universidade de São Paulo, para obtenção do título de Mestre em Bioengenharia.

Curso de Pós-Graduação Interunidades Bioengenharia

ORIENTADOR: Prof. Dr. Helton Luiz Aparecido Defino

Ribeirão Preto 
Agradeço a Deus,

"Inclina o teu ouvido e ouve as palavras dos sábios, e aplica o teu coração à minha ciência".

(Prov. 22:17) 


\section{Dedicatória}

A meu esposo Adriano Vlian Ferreira, pela paciência e compreenssão aos meus filhos Gustavo, Adrieli e Douglas, por tudo que passamos e que só fez fortalecer o meu amor por vocês

À minha mãe e meu pai (in memorian), pela vida, carinho e dedicação. 


\section{AGRADECIMENTOS}

\section{- Ao Prof. Dr. HELTON L. A. DEFINNO, pela orientação,}

\section{"Aplica o teu coração à disciplina e os teus ouvidos às palavras do conhecimento" \\ (Prov. 23:12)}

- Ao estatístico Edilson Ferreira Flores, pela criteriosa realização e pacienciosa orientação da análise estatística:

- Ao Dr. Milton Moacir Garcia, diretor do INSS de Presidente Prudente, e sua secretária Alda, pela grande ajuda na obtenção das guias para os exames radiológicos;

- Às ex-alunas do Curso de Fisioterapia da FCT/UNESP - Campus de Presidente Prudente: Érika Yamada, Fernanda dos Santos Giuranno e Márcia Honji, pela valiosa ajuda na coleta dos dados;

- À Pró-Fisio Clínica de Fisioterapia, especialmente a fisioterapeuta Dra. Márcia Regina Silveira Telli e sua secretária Magda, pela colaboração no sentido de viabilizar a avaliação de vários pacientes;

- Ao Instituto de Radiologia de Presidente Prudente, nas pessoas do Dr. Alberto R. Barbosa e Dr. Jaime R. Barbosa e da secretária Neusa, pela realização dos exames radiográficos;

- Ao Dr. Claudio A. Aranda, pela colaboração e interesse demonstrados;

- Ao Centro de Fratura e Ortopedia São Lucas, nas pessoas do Dr. Damião A.

Grande Lorente e Dr. Ricardo Zuniga Mattos, pelo auxílio prestados;

- À Clínica Nossa Senhora Aparecida, por autorizar a avaliação de pacientes; 
- À minha irmã Silvéria Cristina Albuquerque e nossa amiga Sandra Iara Soares Godelle e todo a sua família, pela maravilhosa acolhida que sempre me proporcionaram em Ribeirão Preto;

- Aos meus amigos: Célia, José Carlos, Carmem Lúcia, Valdeci, Luciane, Carlos, Cristiane e Adriano, pela companhia em aulas, viagens e pelo grande incentivo;

- Ao secretário do Departamento de Fisioterapia da FCT/UNESP - Campus de Presidente Prudente, Marcos Barros de Souza, pela ajuda na revisão final da digitação;

- Aos funcionários e monitor do Polo de Informática Décio, Maria Lúcia e Maurício da FCT/UNESP - Campus de Presidente Prudente, pela ajuda prestada quanto a estruturação deste trabalho;

- À Profa. Cristina Elena Prado Teles Fregonesi do Departamento de Fisioterapia da FCT/UNESP - Campus de Presidente Prudente, pela leitura e correção do trabalho;

- À desenhista Flora da FCT/UNESP - Campus de Presidente Prudente pela elaboração dos desenhos;

- Ao funcionário da FCT/UNESP - Campus de Presidente Prudente, Walmir Cézar Lanza Caldeira pela correção da tradução para o inglês do resumo;

- Às funcionárias do Departamento de Ortopedia e Traumatologia da Faculdade de Medicina de Ribeirão Preto - USP: Fátima, Elizângela e Rose, pela ajuda prestada;

- Aos funcionários da Bioengenharia da USP de São Carlos e de Ribeirão Preto: Marielza, Luiz Paulo, Janete, Luiz Henrique, Chico, Terezinha e Maria, pelo carinho com que sempre me acolheram;

- Aos docentes do Departamento de Fisioterapia da FCT/UNESP - Campus de Presidente Prudente, pois sempre estiveram do meu lado nesta caminhada;

- Aos pacientes, pois sem eles, este trabalho não poderia ser realizado;

- A todos aqueles que, de forma direta ou indireta, favoreceram para que fosse possível a realização deste trabalho. 


\section{SUMÁRIO}

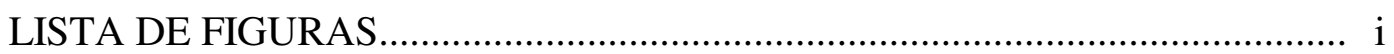

LISTA DE TABELAS................................................................................. ii

LISTA DE ABREVIATURAS E SIGLAS........................................................ v

LISTA DE SÍMBOLOS............................................................................. vi

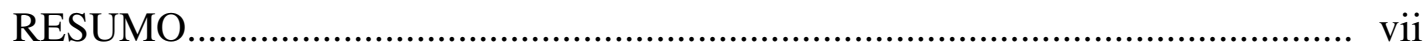

ABSTRACT

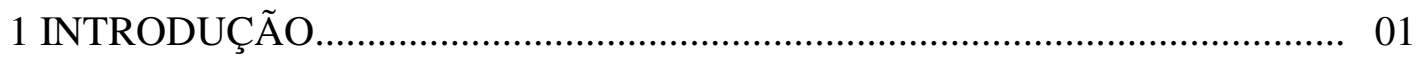

1.1 Métodos radiológicos para mensuração de escoliose....................................... 06

1.2 Métodos de mensuração da gibosidade......................................................... 10

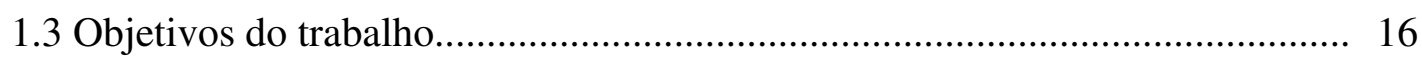

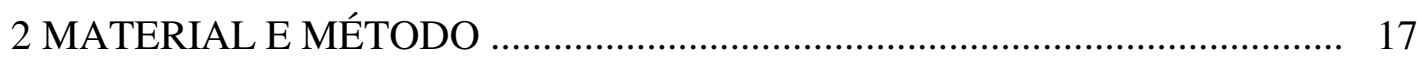

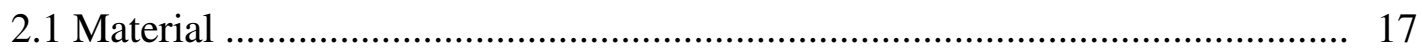

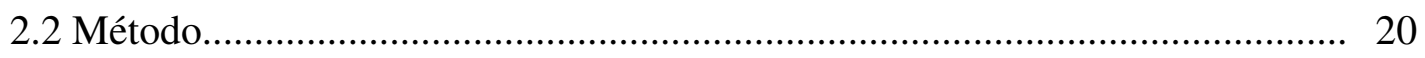

2.3 Análise estatística dos dados......................................................................... 25

3 RESULTADOS ............................................................................ 27

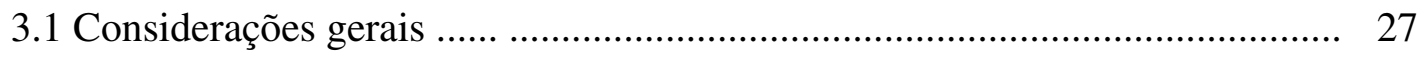

3.2 Medidas de gibosidade entre os três examinadores ......................................... 29

3.3 Medidas de gibosidade nas três posições.......................................................... 31

3.4 Correlação das medidas de gibosidade com as mediada radiológicas na posição ortostática e em decúbito dorsal ............................................................ 33

3.5 Correlação das medidas do ângulo de Cobb com a rotação vertebral pelo método Nash \& Moe e pelo método de Raimondi na posição ortostática e em

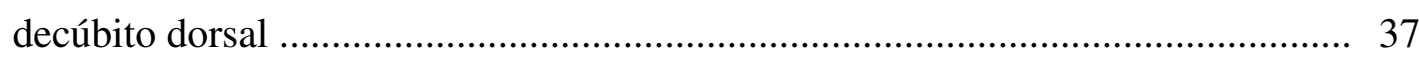


3.6 Comparação da magnitude da curva e da rotação vertebral, mensurada nas radiografias na posição ortostática e em decúbito dorsal................................... 39

4 DISCUSSÃO 41

5 CONCLUSÕES

$\begin{array}{ll}\text { ANEXOS } & 54\end{array}$

REFEÊNCIAS BIBLIOGRÁFICAS 


\section{LISTA DE FIGURAS}

FIGURA 01 - Instrumento usado para medir gibosidade clínica $(\mathrm{cm})$............

FIGURA 02 - A. Régua de Raimondi para medir rotação vertebral (graus);

B. Transferidor para medir o ângulo de Cobb.

FIGURA 03 - A. Esquema utilizado para medir gibosidade clínica, D1= distância da coluna ao ponto mais alto da gibosidade, D2 = mesma distância registrada em D1, AG= altura da gibosidade, $\mathrm{R}=$ rotação; $\mathrm{B}$. Posição 1 para medir gibosidade com um nível d'água e uma régua; C. Posição 2 para medir gibosidade; D. Posição 3 para medir gibosidade.... 22

FIGURA 04 - Reta de regressão obtida da correlação da medida de gibosidade (cm) na posição 2 com o ângulo de Cobb (graus) na posição ortostática nas escolioses torácicas D e E. 34

FIGURA 05 - Reta de regressão obtida da correlação da medida de gibosidade $(\mathrm{cm})$ na posição 3 com a rotação vertebral pelo método de Raimondi (graus) na posição de decúbito nas escolioses tóraco-lombares D e E

FIGURA 06 - Reta de regressão obtida da correlação da medida de gibosidade $(\mathrm{cm})$ na posição 1 com a rotação vertebral pelo método Nash \& Moe (graduação +) na posição ortostática nas escolioses torácicas D e E. 
FIGURA 07 - Reta de regressão obtida da correlação do ângulo de Cobb (graus) com a rotação vertebral pelo método de Raimondi (graus) na posição ortostática nas escolioses lombares D e

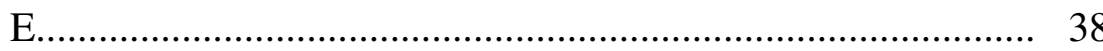




\section{LISTA DE TABELAS}

TABELA 01 - Média, desvio padrão (SD) e limites de idade (anos), peso $(\mathrm{Kg})$ e altura (m) dos 52 pacientes com escoliose idiopática.

TABELA 02 - Determinação da rotação vertebral pelo método NASH \& MOE

TABELA 03 - Média e desvio padrão (SD) das medidas de gibosidade nas regiões torácica direita e esquerda, e lombar direita e esquerda, realizada nas três posições

TABELA 04 - Média, desvio padrão (SD) e limites do ângulo de Cobb nas regiões torácica, lombar e tóraco-lombar direita (D) e esquerda (E)

TABELA 05 - Média, desvio padrão (SD) e limites da rotação vertebral pelo método de Raimondi (graus) nas regiões torácica, lombar e tóraco-lombar D e E.

TABELA 06 - Valores obtidos do resultado do teste de hipótese, nas posições 1, 2 e 3 usando a medida de gibosidade torácica D e E ou lombar D e E, obtida pelos três examinadores.

TABELA 07 - Valores obtidos do resultado do teste de hipótese, nas posições 1, 2 e 3 usando a amplitude da medida de gibosidade torácica D e E ou lombar D e E, obtida pelos três examinadores 
TABELA 08 - Correlação da medida da gibosidade $(\mathrm{cm})$ realizada nas três posições com o ângulo de Cobb (graus) na posição ortostática e decúbito nas escolioses torácica, lombar e tóraco-lombar D e E.

TABELA 09 - Correlação da medida de gibosidade $(\mathrm{cm})$ realizada nas três posições com a rotação vertebral pelo método de Raimondi (graus) na posição ortostática e decúbito nas escolioses torácica, lombar e tóraco-lombar D e E

TABELA 10 - Correlação da medida de gibosidade $(\mathrm{cm})$ realizada nas três posições com a rotação vertebral pelo método Nash \& Moe (graduação +) na posição ortostática e decúbito nas escolioses torácica, lombar e tóraco-lombar D e E 36

TABELA 11 - Correlação do ângulo de Cobb (graus) com a rotação vetebral pelo método de Raimondi (graus) e pelo método Nash \& Moe (graduação +) na posição ortostática e decúbito nas escolioses torácica, lombar e tóraco-lombar D e E.

TABELA 12 - Resultados do teste de hipótese obtidos pela comparação entre as medidas do ângulo de Cobb (graus) na posição ortostática e decúbito nas escolioses torácica, lombar e tóraco-lombar D e E. 39

TABELA 13 - Resultados do teste de hipótese obtidos pela comparação entre as medidas da rotação vertebral pelo método de Raimondi (graus) e pelo método Nash \& Moe (graduação +) na posição ortostática e decúbito nas escolioses torácica, lombar e tóraco-lombar D e E

TABELA 14 - Dados referentes as mensurações de gibosidade, do ângulo de Cobb e da rotação vertebral dos 52 pacientes avaliados com escoliose idiopática (Anexo C) 


\section{LISTA DE ABREVIATURAS E SIGLAS}

Da - Diferença de amplitude das medidas de gibosidade da posição 1 menos a posição 2

$\mathrm{Db} \quad$ - Diferença de amplitude das medidas de gibosidade da posição 1 menos a posição 3

Dc - Diferença de amplitude das medidas de gibosidade da posição 2 menos a posição 3

D - Direita

E - Esquerda

ISIS - Sistema de Imagem do Contorno Integrado

L $\quad$ - Lombar

NBR - Norma Brasileira Registrada

RG - Registro Geral

SD - Desvio Padrão

T $\quad$ - Torácica

TL - Tóraco-lombar

UNESP - Universidade Estadual Paulista 


\section{LISTA DE SÍMBOLOS}

$\begin{array}{ll}\mathrm{cm} & \text { - centímetros } \\ \mathrm{mm} & - \text { milímetros } \\ \mathrm{Kg} & \text { - quilogramas } \\ \mathrm{m} & - \text { metros } \\ \alpha & \text { - nível de significância } \\ \mathrm{n} & \text { - quantidade de elementos na amostra } \\ \mathrm{Ho} & \text { - hipótese nula } \\ \mathrm{r} & \text { - coeficiente de correlação linear de Pearson } \\ \leq & - \text { menor ou igual } \\ < & - \text { menor } \\ \geq & - \text { maior ou igual }\end{array}$




\section{RESUMO}

FERREIRA, D. M. A. (1999). Estudo clínico da mensuração da gibosidade e suas correlações com medidas radiológicas na escoliose idiopática. Ribeirão Preto, 1999. 76p. Dissertação (Mestrado) - Escola de Engenharia de São Carlos, Faculdade de Medicina de Ribeirão Preto e Instituto de Química de São Carlos, Universidade de São Paulo.

Foi realizado um estudo clínico em 52 pacientes com escoliose idiopática para a comparação das mensurações de gibosidade realizadas com uma régua e um nível d'água em três posições (flexão anterior com os membros superiores livres, flexão anterior com as mãos unidas e na posição sentada) e por três examinadores. Foi também estudado a correlação entre essas medidas com a avaliação radiológica na posição ortostática e em decúbito dorsal por meio das medidas do ângulo de Cobb e da rotação vertebral pelo método Nash \& Moe e pelo método de Raimondi, e a comparação da magnitude da curva e da rotação vertebral, mensuradas nas radiografias na posição ortostática e em decúbito dorsal, foi também realizada. Os resultados mostraram uma alta precisão das medidas de gibosidade entre os três examinadores; e quanto as três posições, a posição 1 apresentou uma melhor concordância para mensurar gibosidade, pois quando comparada com a posição 2 e 3 não mostrou diferença significativa. A correlação das medidas de gibosidade com o ângulo de Cobb e com a rotação vertebral foi boa e excelente somente para as curvas torácicas, nas posições 1 e 2 . A correlação do ângulo de Cobb com a rotação vertebral pelo método de Raimondi foi melhor do que pelo método Nash \& Moe nas curvas torácicas e tóraco- lombares. Foram observadas diferenças significativas das medidas do ângulo de Cobb nas radiografias na posição ortostática e em decúbito 
dorsal, mas as medidas de rotação vertebral pelos dois métodos mostraram diferenças significativas apenas nas curvas torácicas e tóraco-lombares.

Palavras-chave: escoliose; mensuração de gibosidade; teste de Adams; ângulo de Cobb; rotação vertebral. 


\begin{abstract}
FERREIRA, D. M. A. (1999). Clínical study of the measurement of hump deformity and their correlation with radiologics measurements in the idiopathic scoliosis. Ribeirão Preto, 1999. 76p. Dissertação (Mestrado) - Escola de Engenharia de São Carlos, Faculdade de Medicina de Ribeirão Preto e Instituto de Química de São Carlos, Universidade de São Paulo.
\end{abstract}

A clinical study were performed in 52 patients with idiopathic scoliosis to the comparison of the measurements of hump deformity performed with a level plane adjusted with a ruler in three positions (forward bending with the upper limb free, forward bending with the hands together and in a position sitting) and by three examiners. This work also studied the correlation among these measurements with the radiologic assessment in erect and supine position through of the measurements of Cobb angle and of the vertebral rotation for the Nash \& Moe and the Raimondi method, and the comparison the curve magnitude and of the vertebral rotation, measured in the radiographs in erect and supine position was performed as well. The results showed a high accuracy of the measurements of hump deformity among the three examiners; and as for the three positions, the position 1 showed a better concordance to measure hump deformity, and when compared with the position 2 and 3 it showed no significant difference. The correlation of the measurements of hump deformity with the Cobb angle and vertebral rotation was good and excellent only for the thoracic curve, at the 1 and 2 positions. Correlation of Cobb angle with vertebral rotation for the Raimondi method was better than for the Nash \& Moe method at the thoracic and thoracolumbar curves. Significant diferences in the Cobb angle measurements at the standing and supine position were observed, but the 
measurements of the vertebral rotation for the two methods showed significant differences only at the thoracic and thoracolumbar curves.

Keywords: scoliosis; measurement of the hump deformity; Adam's test; Cobb angle; vertebral rotation. 


\section{INTRODUÇÃO}

A escoliose, definida por vários autores (GOLDSTEIN \& WAUGH, 1973; CAILLIET, 1977; SURÓS, 1977; PITZEN \& RÖSSLER, 1981; FISCHINGER, 1982; BASMAJIAN, 1987; APLEY, 1989) como sendo um simples desvio lateral da coluna vertebral, tem na verdade uma conotação muito mais complexa, que envolve, não somente o desvio lateral mas uma modificação estrutural das vértebras e costelas com rotação e deformidade, levando a uma topografia irregular da superfície corporal, com uma deformidade que esteticamente gera transtornos, principalmente nas crianças e adolescentes, pelo seu caráter evolutivo, podendo ainda desencadear complicações futuras mais graves em alguns casos.

Nessa última década, o conceito da escoliose, tem mudado, provavelmente devido ao maior entendimento da natureza tridimensional dessa patologia, o que levou a escoliose a ser definida como uma deformidade nos três planos sendo o desvio lateral no plano frontal, a rotação vertebral no plano axial e a lordose no plano sagital (DICKSON, 1983; DEACON, FLOOD, DICKSON, 1984; SMITH \& DICKSON, 1987; DICKSON, 1988; DICKSON \& LEATHERMAN, 1988; CRUICKSHANK, KOIKE, DICKSON, 1989; DICKSON \& LEATHERMAN, 1990; KOJIMA \& KUROKAWA, 1992; PERDRIOLLE et al., 1993; LOPEZ-SOSA, GUILE, BOWEN, 1995).

$\mathrm{O}$ aspecto tridimensional que envolve as deformidades vertebrais principalmente a escoliose, tem levado vários autores, da área médica, ou mesmo engenheiros e engenheiros cartógrafos a pesquisarem técnicas para mensurar a superfície corporal, por meio de medidas tridimensionais do corpo humano (HALLERT, 1960; JEFFRIES et al., 1980; LANE III, 1983; DEACON, FLOOD, DICKSON, 1984; DRERUP \& HIERHOLZER, 1987; STOKES, BIGALOW, 
MORELAND, 1987; TURNER-SMITH et al., 1988; ROSENBERG et al., 1990; SMITH et al., 1991; DRERUP \& HIERHOLZER, 1992 a, b; SKALLI, LAVASTE, DESCRIMES, 1995; THEOLOGIS et al., 1993, 1997).

A frequiência da escoliose apresenta variações dependendo da população estudada, do método de identificação e da quantidade de curva requerida, mas estimativas tem sugerido que a incidência de escoliose na população geral aproxima-se de 2-4\% (BEALS, 1973; BUNNELL, 1986).

A total incidência de escoliose registra extremos de 1 até $13 \%$ por todo o mundo, embora a incidência de escoliose com mais de $10^{\circ}$ em programas de avaliação é de aproximadamente $2 \%$. Existe a necessidade de uma estimação mais exata da incidência de escoliose porque os programas de avaliação são realizados somente em algumas das grandes cidades. Métodos de avaliação e o registro dos resultados de estudos de pacientes com escoliose necessitam ser padronizados (BROOKS et al., 1975; LIU \& HUANG, 1996).

Segundo DICKSON (1983) e DICKSON \& LEATHERMAN (1988), a total prevalência de escoliose pode variar de acordo com a magnitude da curva em graus. Curvas menores que $5^{\circ}$ com $4,5 \%$ de prevalência, curvas entre $5-9^{\circ} \mathrm{com}$ $7,1 \%$; curvas entre $10-14^{\circ}$ com $2,0 \%$; curvas entre $15-19^{\circ}$ com $0,6 \%$ e curvas maiores do que $20^{\circ}$ com prevalência de $0,2 \%$, totalizando $14,4 \%$ de prevalência de escoliose.

DICKSON \& LEATHERMAN (1988), observaram em um estudo com 16.000 crianças uma incidência de $2 \%$ com escoliose, com curvas de $5^{\circ}$ ou mais, medidas pelo ângulo de Cobb, e rotação maior que $5^{\circ}$, medida pelo escoliômetro, confirmados por radiografias. A taxa de prevalência no sexo masculino e feminino aumenta com a idade. Em meninos a taxa de prevalência aos 6 anos é de $0,6 \%$ e aumenta para 2,0\% aos 13 anos. Em meninas a taxa de prevalência aos 6 anos é de $0,7 \%$ e aumenta para $5,0 \%$ aos 13 anos, com o maior aumento ocorrendo durante o rápido crescimento da adolescência.

As deformidades vertebrais na escoliose estão intimamente relacionadas com a sua patogênese, que permanece desconhecida, especialmente na escoliose idiopática, que representa mais de $80 \%$ de todas as escolioses. Consequentemente, muitas hipóteses tem sido apresentadas, focalizando sobre 
fatores genéticos, esqueléticos, miogênicos, tóxico ou químico, mecânico ou biomecânico, neurohormonal e neurogênico. Até agora, nenhuma dessas hipóteses, foi convincente. Podem existir muitas razões para essa falta de consenso, como o fato de que diferentes causas poderiam provocar o mesmo tipo de escoliose ou que uma causa multifatorial poderia envolver as possíveis anormalidades causais nos diferentes níveis (BYRD III, 1988; COILLARD \& RIVARD, 1996).

Segundo STOKES, ARMSTRONG, MORELAND (1988), a deformidade na escoliose idiopática do adolescente, envolve o tronco em geral, as costelas, os órgãos internos, e a aparência da superfície da coluna. A assimetria do tronco pode ser a mais importante para a saúde e estética a longo prazo para o paciente. Embora esteja claro clinicamente que a escoliose e a assimetria da superfície externa do tronco estão relacionadas, a relação quantitativa entre estes dois aspectos da assimetria do tronco são pobremente definidos.

A palavra "gibosidade" é definida como: curvatura da coluna vertebral com elevação exterior (FERREIRA, 1988, p.323). A gibosidade na região torácica é uma proeminência das costelas sobre a convexidade da curva da coluna vertebral, geralmente devido a rotação vertebral que é melhor observada com a flexão anterior do tronco (TERMINOLOGY..., 1976). Na região lombar a gibosidade é uma maior proeminência ou volume da musculatura dessa região, e ambas podem se correlacionar com a magnitude da deformidade espinhal (THULBOURNE \& GILLESPIE，1976; STOKES，ARMSTRONG，MORELAND，1988; STOKES, 1989).

A flexão anterior do tronco, para observar e medir a gibosidade, também conhecida como teste de Adams, transformou-se na posição padrão para detectar escoliose e parece produzir uma acentuação da deformidade da superfície do tronco que é associada a uma deformidade espinhal subjacente nesses pacientes. $\mathrm{O}$ aparente aumento da proeminência da deformidade na superfície do tronco durante a flexão anterior é a base do teste de avaliação em escolares, e é usado extensivamente em todo o mundo (STOKES \& MORELAND, 1987). CARR et al. (1991), acrescentaram que a rotação das vértebras que acompanha a escoliose estrutural causa rotação e deformidade da caixa torácica com elevação do lado da convexidade e depressão do lado da concavidade. 
NISSINEN et al. (1989), relataram que a assimetria deveria ser considerada como um fator de risco na escoliose idiopática do adolescente, e que uma em cada quatro crianças apresentam assimetria de tronco na idade de dez anos. Porém ainda não se conhece que tipo ou qual medida dessa assimetria de tronco pode ser considerada fisiológica nas diferentes idades.

Um importante fator na deformidade da escoliose idiopática é a rotação axial vertebral que acompanha o desvio lateral vertebral. Interações mecânicas dentro da coluna tem implicado em causar rotação vertebral com desvio lateral (ARKIN, 1950). Essa rotação é imaginada como sendo significante para o início e progressão da escoliose. A magnitude da rotação axial correlaciona com o desvio lateral de vértebras no eixo da coluna e a rotação é máxima perto do ápice da curva. (STOKES, BIGALOW, MORELAND, 1987; STOKES, ARMSTRONG, MORELAND, 1988; DICKSON \& LEATHERMAN, 1990). A rotação axial usualmente desvia o processo espinhoso para a concavidade da escoliose. A causa dessa interação entre desvio lateral e rotação axial não é bem entendida (STOKES \& GARDNER-MORSE, 1991).

STOKES (1991), relata que pacientes com deformidades escolióticas podem ser avaliados de um ponto de vista biomecânico por mensurações da morfologia vertebral, pela topografia da superfície do tronco, e por alterações nessas mensurações tanto agudamente como através do tempo. Estas técnicas de mensurações tem proporcionado informações sobre a deformidade vertebral e seu tratamento. SCHULTZ (1991), contempla esta idéia quando diz que a escoliose é uma condição física que é definida em termos mecânicos, mas acrescenta que o valor de estudos biomecânicos é talvez menos aceito, mas apesar disso, estes estudos na escoliose são necessários.

SMITH \& FERNIE (1991), estudando a biomecânica funcional da coluna relataram que a coluna vertebral, quando curvada dentro do seu estado normal, mais ainda sob condições de escoliose é um sistema inerentemente instável, requerendo suporte muscular ativo para manter sua postura. A progressão de uma curva escoliótica pode ser vista como uma deformação planejada em escalas combinadas por alterações devido ao crescimento. A presença da rotação axial combinada com a inclinação lateral, pode contribuir para o desenvolvimento das 
curvas escolióticas exageradas. A deformidade do corpo vertebral que acompanha a escoliose vai destruindo qualquer simetria axial e adicionando um estado de desequilíbrio.

O conhecimento insuficiente da biomecânica da deformidade na caixa torácica na escoliose é um problema fundamental. CLOSKEY \& SCHULTZ (1993), desenvolveram um estudo por meio de um modelo biomecânico computadorizado que simula o comportamento da coluna tóraco-lombar e das deformações da caixa torácica, para examinar que fatores poderiam controlar esta deformidade. Uma das constatações interessantes neste estudo foi que a maior distorção da costela estava associada com uma grande rotação vertebral e um pequeno ângulo de Cobb. Por outro lado, uma maior rotação vertebral nem sempre estava associada com uma maior rotação da caixa torácica, sugerindo pelo modelo biomecânico que a rotação vertebral não é o único determinante da rotação da caixa torácica.

As deformidades vertebrais que acompanham a escoliose também são alvos de pesquisas, mostrando que tanto o corpo como os elementos posteriores sofrem modificações nos três planos, devido a característica tridimensional da deformidade encontrada em vértebras humanas de cadáver e em animais de estudo (XIONG et al., 1995; COILLARD \& RIVARD, 1996).

JEFFRIES et al. (1980), comentaram que a avaliação radiológica é importante no controle da escoliose de três maneiras: confirma sua presença, auxilia na determinação da etiologia e flexibilidade da deformidade, e quantifica o grau inicial da curvatura do tronco e qualquer alteração subseqüente a uma terapia.

GUNZBURG et al. (1991), relatam que a habilidade para mensurar rotação vertebral acuradamente na radiografia em ântero-posterior é clinicamente importante, pois é uma técnica de baixo custo, requer pouca radiação, e de acordo com autoridades sobre o assunto, se interpretado corretamente, ela é segura. Esta precisão, entretanto, depende grandemente dos pontos de referência radiológicos.

A importância de detectar precocemente a escoliose reside no fato de que o tratamento, mesmo nas escolioses leves, pode ser iniciado com o objetivo de, pelo menos, observar a evolução do quadro ou indicar tratamentos não-operatórios, embora estes nem sempre apresentam bons resultados (ROWE et al., 1997). 
Por ser um tema tão abrangente, a escoliose tem conduzido pesquisas, principalmente no que diz respeito a deformidade produzida na superfície corporal, e a sua relação com a deformidade anatômica estrutural pela rotação dos corpos vertebrais e a magnitude da angulação na curva escoliótica. Portanto, este estudo, tem o propósito de determinar a concordância das mensurações da gibosidade e correlacionar com os aspectos estruturais das medidas radiológicas em indivíduos com escoliose idiopática.

\subsection{Métodos radiológicos para mensuração da escoliose}

COBB em 1948 (DICKSON \& LEATHERMAN 1988), elaborou um método conhecido como ângulo de Cobb para mensurar o tamanho da curva na escoliose, utilizando radiografia padrão. Para realizar essa mensuração, identifica-se a vértebra superior e inferior da curva, que são aquelas com a máxima inclinação para a concavidade. Uma linha é traçada paralela à borda superior da vértebra superior e outra linha paralela à borda inferior da vértebra inferior. O ângulo de Cobb é formado pela intersecção dessas linhas. Se a curva é de pequena magnitude, então as duas linhas não se encontram sobre o filme da radiografia e, portanto será necessário traçar perpendiculares a essas linhas, até que as mensurações possam ser feitas sobre a radiografia.

SEVASTIKOGLOU \& BERGQUIST (1969) realizaram um estudo para avaliar a precisão de métodos radiológicos no registro de escoliose. Foram usados o método de Ferguson e o método de Cobb. As mensurações realizadas pelo método de Cobb apresentaram consistentemente valores mais altos do que aquelas realizadas pelo método de Ferguson. Não existiu, portanto, nenhuma apreciável diferença entre mensurações realizadas pelos dois métodos.

A importância da rotação vertebral na etiologia e tratamento da escoliose é bem reconhecida. COBB em 1948 (NASH \& MOE 1969), descreveu uma técnica padrão para mensurar a rotação vertebral baseado sobre a posição do processo espinhoso em relação a base do corpo vertebral. Mais tarde NASH \& MOE 
(1969), perceberam que esse método não era seguro devido ao desenvolvimento assimétrico do processo espinhoso da coluna escoliótica. Esses autores introduziram o seu próprio método que determina o grau de rotação de um segmento vertebral pela posição dos pedículos em relação a margem lateral do corpo vertebral. O método é determinado pela relação entre a sombra dos pedículos observada nas radiografias ântero-posterior, com a margem lateral do corpo vertebral. Quando os pedículos estão eqüidistantes (distâncias iguais) da margem lateral do corpo vertebral, a vértebra está neutra. Quando a sombra oval do pedículo está mais distante da margem lateral do corpo vertebral, a vértebra está rodada para aquele lado.

O método de Cobb é universalmente utilizado, sendo inclusive recomendado pela "Scoliosis Research Society of North America" como sendo o método mais seguro (GOLDSTEIN \& WAUGH, 1973; CHAPCHAL \& WAIGAND, 1973; CAILLIET, 1977; KISNER \& COLBY, 1987).

PERDRIOLLE \& VIDAL (1981), usaram um torsiômetro que é uma régua especial cujo posicionamento sobre a radiografia fornece o grau de rotação vertebral na escoliose. Esse método também é conhecido como método de Perdriolle e vários autores vem utilizando-o em pesquisas (GRANATA et al., 1989; GUNZBURG et al., 1991; RICHARDS, 1992; ÖMEROGLU, ÖZEKIN, BIÇIMOGLU, 1996).

Radiografias tem sido a mais exata maneira para avaliar o grau de deformidade no diagnóstico e tratamento de escoliose. Devido ao fato dos pacientes passarem por um longo período de tratamento, são necessárias periódicas avaliações radiológicas, e tem aumentado a preocupação com os riscos de radiação. Alguns estudos foram realizados no sentido de detectar e diminuir os riscos que a radiação pode causar nesses pacientes (NASH et al., 1979; ARDRAN et al., 1980; KOGUTT, WARREN, KALMAR, 1989). O uso de métodos não invasivos de mensuração de escoliose, também podem ser uma alternativa, para acompanhar a evolução das escolioses idiopáticas, diminuindo assim o uso das radiografias, porém estas, nunca poderão ser excluídas dos programas de avaliação de escoliose.

A mensuração da rotação axial de vértebras na escoliose também foi realizada por meio da técnica de estereoradiografias usando duas projeções radiológicas que permitiam o cálculo da rotação axial por meio de uma fórmula 
matemática simples. Os autores concluem que estas mensurações são sensíveis a erros, e acrescentam que esta precisão é improvável de ser melhorada futuramente (STOKES, BIGALOW, MORELAND, 1986; STOKES, DANSEREAU, MORELAND, 1989).

DRERUP (1984), DRERUP \& HIERHOLZER (1992 a, b), utilizaram uma mensuração de rotação vertebral baseada no método de Nash \& Moe, por meio de radiografias no plano frontal. O método consiste de um sistema de coordenadas onde os dados são digitados em um programa que faz uso de um complexo procedimento matemático, que se traduz nas mensurações e relações entre o desvio lateral, inclinação lateral e rotação axial das vértebras com escoliose.

Devido ao fato da escoliose ser uma deformidade com rotação, a visão radiológica ântero-posterior convencional do paciente escoliótico contém consideravelmente mais informações tridimensionais do que é o caso de colunas que não são rodadas. No estudo de CRUICKSHANK, KOIKE, DICKSON (1989), o objetivo foi mostrar que o perfil sagital de cada nível rodado pode também ser demostrado qualitativamente sobre projeção ântero-posterior e que uma avaliação global pode ser feita do perfil nos diferentes níveis da curva estrutural.

Os resultados de muitos estudos de pacientes que tem escoliose ou cifose são baseados na precisão de mensurações de radiografias. Os tratamentos são escolhidos com base no grau de curvatura ou na progressão da curva. Uma vez que os efeitos dos tratamentos são maiores, é importante que a precisão das mensurações seja bem documentada e que os próprios métodos estatísticos sejam usados para evitar superestimação das alterações que podem ser produzidas somente por erro de examinador (CARMAN, BROWNE, BIRCH, 1990).

RUSSELL et al. (1990), na sua pesquisa avaliou quatro métodos para mensuração de rotação vertebral, em um modelo tridimensional, construído in vitro com deformidade vertebral e estética por escoliose. Os métodos analisados foram de Bunnel, Drerup, Koreska e Stokes, sendo que o método de Bunnel foi o que aparentemente forneceu um resultado mais consistente.

MORRISSY et al. (1990), quantificaram o erro intrínseco da mensuração do ângulo de Cobb nas radiografias de pacientes com escoliose, e enfatizou a importância e necessidade de anotar precisamente as vértebras nos 
extremos da curva e ter sempre uma única pessoa para realizar as mensurações nas radiografias, neste caso existe $95 \%$ de chance do erro na mensuração ser menor do que 3 graus.

DUVAL-BEAUPÈRE (1992), relata que o uso do ângulo da curva escoliótica na posição de decúbito dorsal para prognóstico pode parecer incomum, porque uma radiografia nessa posição não é sempre incluída no protocolo radiológico para o primeiro exame de pacientes escolióticos. É praticamente impossível fazer um prognóstico individual razoavelmente certo da escoliose com o ângulo da curva na posição ortostática sozinho, quando ela é menor do que $30^{\circ}$, o tamanho do ângulo da curva na posição de decúbito dorsal poderia ser um caminho de obter um prognóstico individual para escoliose mínima, especialmente se está associada a mensuração da gibosidade, enquanto o ângulo na posição ortostática fornece uma indicação do estado funcional da coluna.

HO et al. (1992), compararam dois métodos para medir rotação vertebral em escoliose idiopática do adolescente: o método Nash \& Moe em radiografia ântero-posterior na posição de decúbito dorsal e um novo método usando tomografia computadorizada. Os resultados não mostraram diferenças significativas entre os dois métodos.

Clinicamente, uma idéia qualitativa da rotação axial, pode ser obtida de radiografia padrão no plano frontal. É geralmente aceito que estes métodos, que na grande maioria são baseados sobre a sombra dos pedículos, possam ter uma precisão de aproximadamente $5^{\circ}$, e o resultado é melhor se a rotação axial é menor do que $40^{\circ}$. No entanto, a necessidade de precisão é bem maior quando mensurações são feitas para propósitos de pesquisas (SKALLI, LAVASTE, DESCRIMES, 1995).

WEISS (1995), descreve o uso do método de Raimondi para medir rotação vertebral. O autor mensurou a rotação vertebral de 40 curvas em 20 radiografias ântero-posterior pelo torsiômetro de Perdriolle e pelo método de Raimondi e testou a precisão dessas medidas. Ambos métodos demostraram ser ferramentas úteis para o acompanhamento de rotação vertebral quando projetados de radiografias padrão por clínicos experientes. O método de Raimondi é mais fácil de usar e é ligeiramente mais seguro e apresenta uma graduação de dois em dois graus, enquanto no torsiômetro de Perdriolle é de cinco em cinco graus. 
KRISMER et al. (1996), também usaram um método para mensurar rotação vertebral axial em cadáveres por meio de tomografia computadorizada, porém, destacaram alguns erros casuais como: má visualização dos pontos de referências ósseas, torção mecânica da vértebra conduzindo a diferentes ângulos de rotação nos diferentes níveis e exploração oblíqua causada pela rotação no plano frontal e sagital, dificultando a visualização dos pedículos.

MIOR et al. (1996), usaram um instrumento computadorizado eletrogoniométrico, conhecido como Sistema de Análise Esquelética Metrecom que estima o tamanho da curva escoliótica pela avaliação do contorno dos processos espinhosos na superfície do tronco, porém o sistema não proporcionou uma precisão clínica para substituir a mensuração do ângulo de Cobb de radiografias em pacientes com escoliose.

BIRCHALL et al. (1997), utilizaram uma técnica para mensurar rotação axial através de imagem de ressonância magnética em dez pacientes com escoliose idiopática e correlacionou com a rotação mensurada de radiografia usando o torsiômetro de Perdriolle. A técnica é altamente reproduzível, com insignificante variação estatística, embora sua exatidão absoluta dependa de uma referência em relação a uma vértebra em posição de rotação neutra.

SHEA et al. (1998), analisaram a variabilidade de mensurações do ângulo de Cobb sobre radiografias digitais e compararam com medidas manuais sobre radiografias padrões. Os resultados mostram vantagens e desvantagens dos dois métodos e constatam que ambos apresentam uma variação de aproximadamente 3 graus.

\subsection{Métodos de mensuração da gibosidade na escoliose}

A relação entre a deformidade da superfície do tronco (gibosidade) e a deformidade vertebral na escoliose não é bem documentada. Tradicionalmente, o uso de radiografias póstero-anterior e ântero-posterior e mensurações associadas tem sido os métodos primários para registrar e documentar a escoliose. ADAMS em 1865 
(STOKES \& MORELAND 1989), usou moldes de gesso da superfície do tronco como um método primário para registrar a deformidade e demonstrar os efeitos do tratamento. A superfície do tronco tem também uma significância subjetiva devido a sua importância estética.

VINCHON (1965), apresentou um aparelho que permitia medir gibosidade na escoliose usando uma régua na posição horizontal e duas outras réguas encaixadas na posição vertical, para realizar a medida em centímetros.

Segundo THULBOURNE \& GILLESPIE (1976), na escoliose idiopática a gibosidade é a característica da deformidade mais ressentida pelo paciente, menos entendida pelo cirurgião e mais resistente ao tratamento. Os autores usaram um método simples de mensurar a deformidade das costelas e analisar sua relação com a curvatura lateral pelo ângulo de Cobb, com a rotação vertebral pelo método Nash \& Moe e com o ângulo costo-vertebral pelo método de Mehta (MEHTA, 1972). O instrumento consiste de uma série de faixas móveis, que acompanham um nível d'água e que era colocado na superfície do tronco do paciente e a medida era feita com flexão anterior da coluna e mãos juntas.

CAILLIET (1977), usou um instrumento composto de três réguas para medir o lado côncavo e convexo da curva e usou também, um instrumento com uma agulha oscilante sobre uma bolha de ar e assim fornecia o ângulo da obliqüidade numa escala em graus. SURÓS (1977), também usou um hidrogoniômetro de Rippstein, que fornecia uma medida em graus, assim como, fez uso de uma medida mais simples, por meio de uma régua e um nível d'água, que fornecia em centímetros a quantidade de gibosidade presente.

Vários autores usaram técnicas de bioestereometria, ou seja, as aplicações da fotogrametria à curta distância no campo da medicina para medir formas e dimensões do corpo humano (NEWTON, 1980). Algumas pesquisas foram realizadas em pacientes com escoliose ou outras deformidades da coluna (DRERUP, 1981; STOKES, 1989; STOKES \& MORELAND, 1989; FROBIN \& HIERHOLZER, 1981, 1983 a, b; ELAD \& EINAV, 1990; FROBIN \& HIERHOLZER, 1991). Esses autores realizaram uma técnica de mensuração tridimensional para análise e avaliação da superfície da coluna vertebral por meio de um procedimento computadorizado sem contato, baseado nos princípios da raster- 
estereofotografia, ou seja, pelo uso de câmara de vídeo, de fotografia e retro-projetor ou pela análise numérica dos topogramas de Moiré.

VERCAUTEREN et al. (1982), investigaram a assimetria do tronco em 270 escolares com um nível d'água e uma régua para medir gibosidade (com flexão anterior) e a altura discrepante dos ombros, escápulas e cristas ilíacas (em ortostático). E constataram que uma gibosidade torácica que não excede $0,8 \mathrm{~cm}$ e uma lombar com $0,5 \mathrm{~cm}$ podem ser consideradas fisiológicas.

BURWELL et al. (1983), usaram um aparelho na posição de flexão anterior, que formulava um traçado do contorno do tronco em escolares saudáveis e padronizaram uma classificação das assimetrias da coluna baseada no uso desse aparelho e de outras parâmetros como idade, sexo, localização da deformidade e medidas radiológicas.

BUNNELL \& DELAWARE (1984) e BUNNELL (1993), desenvolveram um aparelho chamado escoliômetro para mensuração do ângulo de rotação do tronco. O aparelho é colocado na superfície do tronco, e portanto se baseia no deslocamento dos elementos posteriores, fornecendo o ângulo de inclinação torácica e lombar. AMENDT et al. (1990); MURRELL et al. (1993); KOROVESSIS \& STAMATAKIS (1996), testaram a validade e a precisão do escoliômetro, através da correlação com medidas radiológicas. HUANG (1997), também utilizou o escoliômetro para avaliar estudantes, através do teste de flexão anterior de Adams. CÔTÉ et al. (1998), realizaram um estudo comparando a exatidão e precisão do escoliômetro com o teste de flexão anterior de Adams.

DUVAL-BEAUPÈRE \& LAMIREAU (1985), realizaram um estudo em indivíduos com escoliose, onde constataram que a altura da gibosidade está diretamente correlacionada com a velocidade de progressão da escoliose. A gibosidade foi medida com um nível d'água na posição sentada, com flexão anterior do tronco.

STOKES \& MORELAND (1987), usaram a técnica de rasterestereofotografia em 56 pacientes com escoliose idiopática em três posições (na posição ortostática, na posição de flexão anterior com as mãos entre os joelhos e na posição de flexão anterior com as mãos tocando os dedos do pé), e observaram que qualitativamente a rotação na superfície do tronco (gibosidade) era similar nas três 
posições, porém, na região lombar a posição de flexão anterior aumentava essa rotação.

TURNER-SMITH et al. (1988), utilizaram o "Sistema de Imagem do Contorno Integrado", conhecido como ISIS, e o ângulo de Cobb de radiografias em ântero-posterior para correlacionar com as assimetrias detectadas nos três planos, ou seja, a assimetria lateral no plano coronal com a análise do formato do tronco, a assimetria no plano transverso estimando a rotação vertebral pela medida da gibosidade e a assimetria no plano sagital pela visualização da cifose ou lordose do tronco. CARR et al. (1989, 1991) e THEOLOGIS et al. (1993, 1997), também utilizaram a técnica ISIS para mensurar o contorno do tronco em pacientes com escoliose.

NISSINEN et al. (1989), utilizaram um nível d'água e o inclinômetro em escolares para avaliar a assimetria do tronco e escoliose, por meio do teste de flexão anterior e a radiografia padrão para mensurar o ângulo de Cobb. O tamanho da gibosidade em milímetros e em graus era maior em garotas e a maioria das crianças (61\%) tinham gibosidade de 1-5mm; 20\%, aproximadamente, tinham gibosidade de $6 \mathrm{~mm}$ ou mais. Existiu uma correlação positiva entre o tamanho da gibosidade e o ângulo de rotação do tronco medido pelo inclinômetro; e uma discreta correlação entre o tamanho da gibosidade e o ângulo de Cobb.

DUVAL-BEAUPÈRE (1992), em outra pesquisa utilizando novamente uma régua e um nível d'água, declarou a importância de detectar o tamanho do ângulo da curva na posição de decúbito dorsal, a altura da gibosidade, o padrão escoliótico e o estado de maturação para determinar o índice de progressão da escoliose. O conhecimento destes parâmetros foram usados para fazer prognósticos em aproximadamente $95 \%$ dos pacientes estudados, que apresentaram ângulo de Cobb em decúbito dorsal inicial maior que $17^{\circ}$, ou gibosidade maior que $11 \mathrm{~mm}$, mostrando que estes podem apresentar escoliose progressiva.

PEARSALL, REID, HEDDEN (1992), realizaram uma pesquisa com 14 pacientes com escoliose idiopática do adolescente, que foram submetidos a três métodos não invasivos para mensurar a gibosidade, por meio do contorno do tronco. Utilizaram o escoliômetro, um aparelho para medir o contorno do tronco (back contour device), e o uso da imagem topográfica de Moiré, e correlacionaram com 
medidas radiológicas do ângulo de Cobb em ântero-posterior. Os resultados sugerem que a técnica pode proporcionar uma estimação válida da curvatura lateral da coluna na região torácica, mas não na região lombar; mas acrescentam que estas técnicas de mensuração não invasivas poderiam ser utilizadas como parte de um programa de avaliação física objetiva para a precoce detecção de escoliose pois elas mostraram ser sensitivas com relação a deformidades na região torácica, onde a condição escoliótica normalmente ocorre, entretanto, para um diagnóstico clínico exato de toda a coluna, a investigação radiológica é ainda necessária.

NISSINEN et al. (1993), usaram uma régua e um nível d'água para medir gibosidade durante três anos em escolares e declararam que em garotos e garotas a medida da assimetria do tronco pelo teste de inclinação anterior é o mais poderoso determinante de incidência de escoliose.

Medidas não invasivas também são usadas como base de dados para estimação do movimento vertebral normal como relata o estudo de GRACOVETSKY et al. (1995), que mostrou que é possível estimar o movimento vertebral por meio de marcas colocadas na superfície da pele do tronco, e estas mensurações comparam favoravelmente com dados radiológicos.

DUVAL-BEAUPÈRE (1996), em pesquisa mais recente, e usando a mesma metodologia, observou que muitos casos de escoliose com ângulo de Cobb na posição de decúbito dorsal ou ortostática e a medida da gibosidade abaixo do valor limite, $17^{\circ}, 24^{\circ}$ e $11 \mathrm{~mm}$, respectivamente, demonstraram uma maior progressão, consequentemente nenhum prognóstico pode ser feito com base nestes parâmetros, e a monitoração é necessária, especialmente se a criança está atravessando a puberdade, neste caso as avaliações deveriam ser a cada três meses. Se na primeira avaliação de um paciente com escoliose, os três parâmetros excedem os valores limites citados anteriormente, o risco de progressão é bem maior.

SCUTT, DANGERFIELD, DORGAN (1996), sugerem que a adoção de uma posição padronizada para a mensuração da deformidade da superfície e radiológica permitirá consistência de julgamentos clínicos baseados nestes parâmetros. Os autores investigaram 27 pacientes com escoliose idiopática do adolescente, realizando medidas do ângulo de inclinação torácica com um escoliômetro em três posições: flexão anterior na posição ortostática, flexão anterior 
sentado, e em decúbito ventral sobre uma maca especial. O ângulo de Cobb foi mensurado nas radiografias em ântero-posterior, a rotação vertebral usando o torsiômetro de Perdriolle e a rotação do processo espinhoso usando o aparelho de Bunnel modificado. Os resultados mostraram que a maior deformidade da superfície do tronco nem sempre coincide com a maior deformidade radiológica. A mensuração da rotação vertebral pelo processo espinhoso mostrou valores mais baixos daquela feita pelos pedículos. O estudo conclui que as medidas dos ângulos de inclinação torácica na posição de decúbito ventral demonstraram uma melhor correlação com as mensurações radiológicas da rotação vertebral e do ângulo de Cobb em curvas duplas.

SOUCACOS et al. (1997), estudaram a prevalência e distribuição de vários parâmetros associados com escoliose em escolares. $\mathrm{O}$ teste de flexão anterior com os membros superiores pendentes e relaxados foi realizado, inicialmente, apenas observando assimetrias no tronco e, posteriormente, para confirmar foram mensurados com uma régua e um nível d'água, onde se utilizou um critério que quando a diferença era maior do que cinco milímetros, considerava-se um achado positivo no teste de flexão anterior. Posteriormente estas crianças eram avaliadas radiologicamente para confirmar o resultado positivo do teste. As curvas de $10^{\circ}$ ou mais eram consideradas escoliose estrutural. Das 4185 crianças avaliadas por radiografia, 1402 tinham um achado radiológico negativo, ou seja, o teste detectou assimetria, mas radiologicamente não havia escoliose. A avaliação de crianças com escoliose usando um teste simples parece ser um efetivo meio para a precoce detecção e tratamento não operatório de escoliose e outras deformidades vertebrais.

D`OSUALDO, SCHIERANO, IANNIS (1997), utilizaram o arcômetro, para mensurar a cifose. Os autores avaliaram a concordância entre mensurações clínicas da superfície e mensurações radiológicas da cifose e os resultados mostraram que o instrumento é razoavelmente prático e seguro, mas existiu considerável desacordo com as radiografias e algumas variações entre observadores e observações. Por ser um instrumento simples e facilmente reproduzível, os autores sugerem que a mensuração pelo arcômetro possa ser usada no acompanhamento de pacientes já avaliados radiologicamente e na avaliação da população. 
GRAM \& HASAN (1999), estudaram 19 crianças com escoliose idiopática, por meio de medidas radiológicas na posição ortostática e de medidas tridimensionais do tronco com o uso de câmaras fotográficas na posição ortostática relaxada, na posição sentada relaxada, na posição sentada ereta e na posição sentada escrevendo. Os resultados mostraram que os ápices das curvas nos pacientes com escoliose sofreram alterações na posição ortostática e sentada relaxada, dependendo do número, localização e direção dos mesmos na coluna vertebral.

\subsection{Objetivos do trabalho}

O trabalho foi realizado com o propósito de avaliar diferentes aspectos clínicos relacionados à deformidade vertebral observada na escoliose idiopática, tendo sido estabelecido os seguintes objetivos específicos no estudo:

1.3.1. Comparação das mensurações da gibosidade clínica em pacientes com escoliose idiopática em três diferentes posições e por três examinadores;

1.3.2. Correlação das medidas da gibosidade com a avaliação radiológica na posição ortostática e em decúbito dorsal por meio das medidas do ângulo de Cobb e da rotação vertebral pelo método Nash \& Moe e pelo método de Raimondi;

1.3.3. Correlação das medidas do ângulo de Cobb com a rotação vertebral pelo método Nash \& Moe e pelo método de Raimondi, na posição ortostática e em decúbito dorsal;

1.3.4. Comparação da magnitude da curva e da rotação vertebral nas escolioses idiopáticas, mensurada nas radiografias realizadas na posição ortostática e em decúbito dorsal. 


\section{MATERIAL E MÉTODO}

\subsection{Material}

Foram avaliados 52 pacientes, 18 do sexo masculino e 34 do sexo feminino (TABELA 1), diagnosticados com escoliose idiopática e encaminhados por médicos ortopedistas da cidade de Presidente Prudente e região, sendo submetidos, inicialmente, a um exame clínico, após assinarem o termo de consentimento para participação em pesquisa científica (Anexo A). Do total, 48 pacientes foram submetidos a exame radiológico sendo que 43 na posição ortostática e na posição de decúbito dorsal, e cinco só realizaram a radiografia na posição ortostática.

TABELA 1 - Média, desvio padrão (SD) e limites de idade (anos), peso ( $\mathrm{Kg}$ ) e altura (m) dos 52 pacientes com escoliose idiopática.

\begin{tabular}{lccc}
\hline \hline & Idade & Peso & Altura \\
\hline Média & 19,56 & 55,84 & 1,65 \\
SD & 7,44 & 12,54 & 0,11 \\
Limites & $8-34$ & $30-92$ & $1,32-1,95$ \\
\hline \hline
\end{tabular}

Os materiais utilizados para realizar as mensurações da gibosidade, comprimento dos membros inferiores e as medidas radiológicas foram:

a) Um instrumento para medir gibosidade clínica, segundo orientação de SURÓS (1977), que é constituído por um nível d'água de madeira de $35,8 \mathrm{~cm}$ de comprimento, $5,4 \mathrm{~cm}$ de largura e 2,2 $\mathrm{cm}$ de espessura, que é adaptado com um orifício que permite o encaixe de uma régua de madeira de $30 \mathrm{~cm}$, e sobre o mesmo 
estão fixadas duas réguas de $20 \mathrm{~cm}$ de ambos os lados, para orientação das mensurações (FIGURA 1);

b) uma folha quadrada de papel cartão, com o desenho da impressão plantar, separadas por uma distância de $10 \mathrm{~cm}$ e paralelas;

c) um banco de madeira com assento quadrado e com aproximadamente $50 \mathrm{~cm}$ de altura;

d) uma fita métrica com $150 \mathrm{~cm}$ de comprimento para medir o comprimento dos membros inferiores;

e) uma régua de Raimondi para medir rotação vertebral (FIGURA 2 A);

f) um transferidor para medir o ângulo de Cobb (FIGURA 2 - B). 


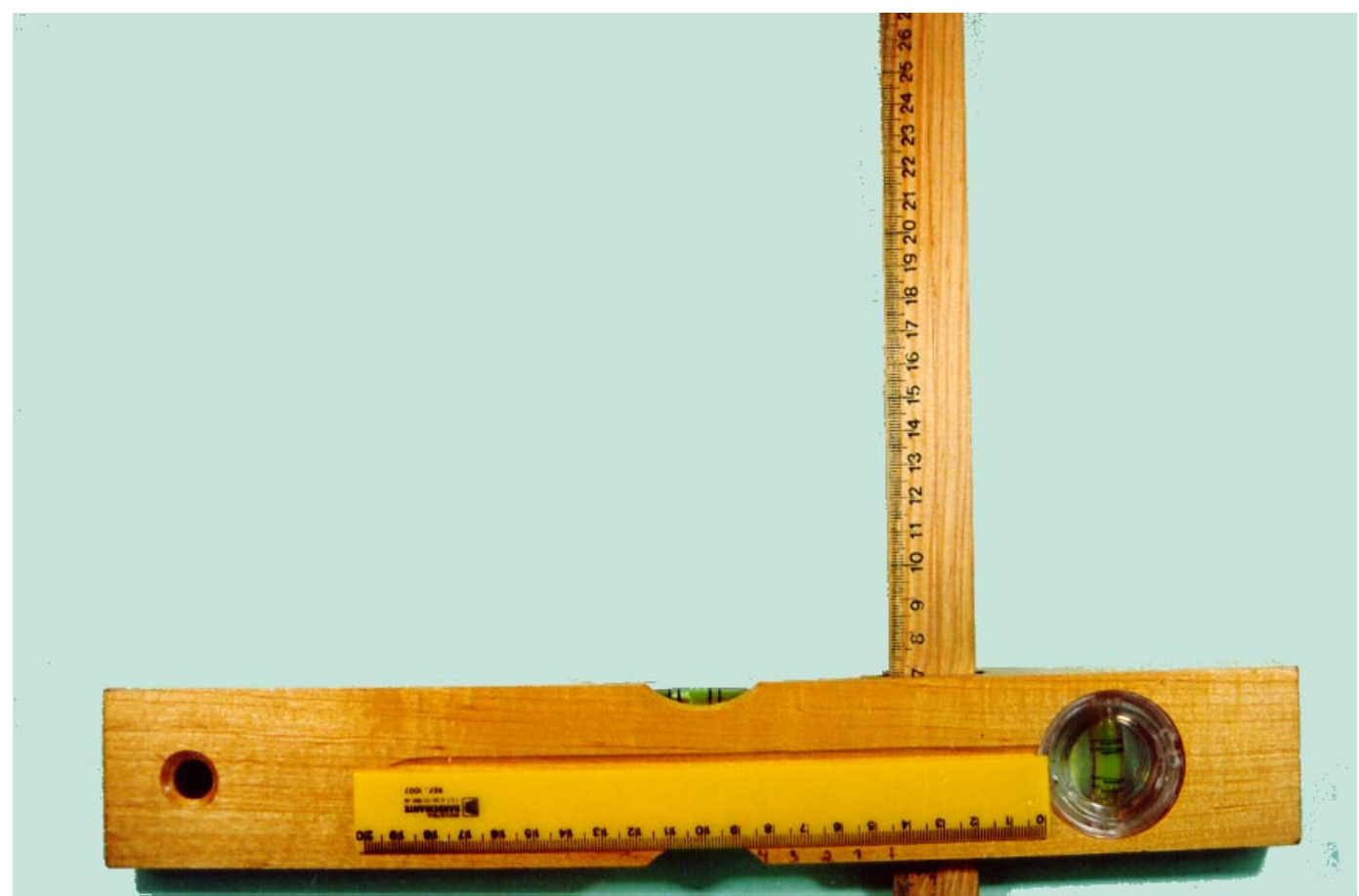

FIGURA 1 - Instrumento usado para medir gibosidade $(\mathrm{cm})$.

A

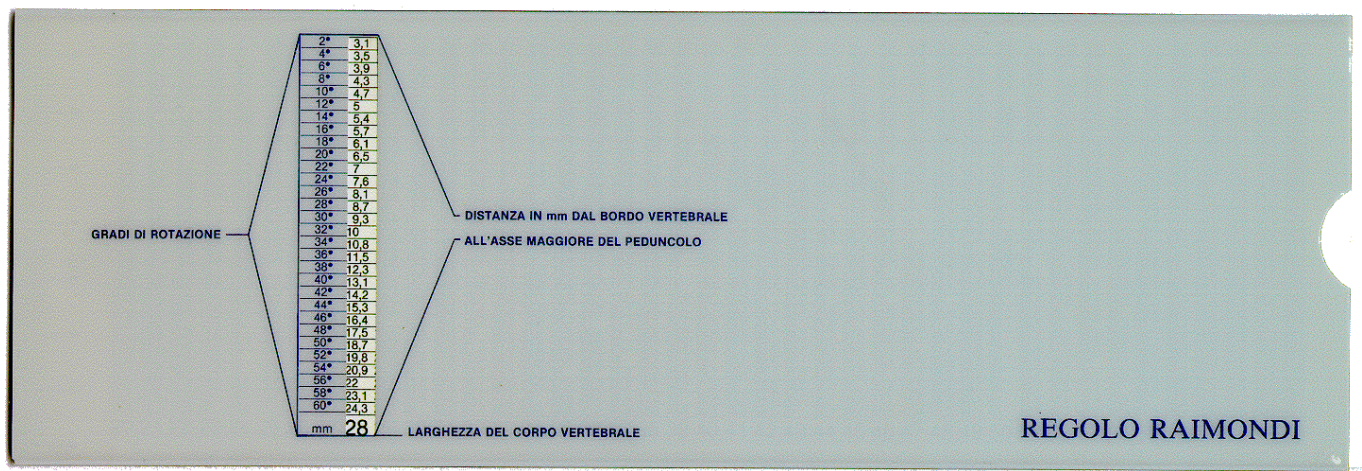

B

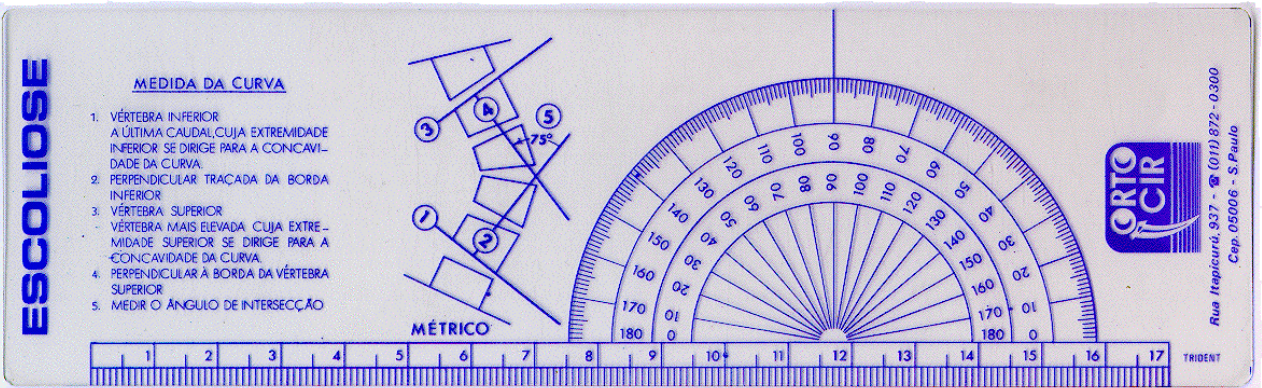

FIGURA 2 - A. Régua de Raimondi para medir rotação vertebral (graus); B. Transferidor para medir o ângulo de Cobb (graus). 


\subsection{Método}

A coleta dos dados foi realizada por meio de uma Ficha de Avaliação para Escoliose (Anexo B), especificamente elaborada para essa pesquisa, que consta dos seguintes dados:

\section{A) Dados pessoais}

São os dados referentes a nome, idade, sexo, peso, altura, endereço, profissão, diagnóstico, número do registro geral $(R G)$ e o nome do médico responsável.

B) Exame clínico

1) Menarca - registrar a idade que ocorreu a primeira menstruação.

2) Mensuração dos membros inferiores - foi realizada a medida real dos membros inferiores, na qual o paciente permanecia em decúbito dorsal sobre uma superfície plana e o comprimento era registrado com uma fita métrica apoiada na crista ilíaca ântero-superior até o maléolo interno (HOPPENFELD, 1980). Os pacientes que apresentavam assimetria maior que $1,0 \mathrm{~cm}$ na medida real dos membros inferiores, era solicitado um escanograma para quantificação mais exata da assimetria constatada.

3) Mensuração da gibosidade - constou de inspeção visual, com o tronco despido, em seguida a gibosidade clínica foi mensurada com um nível d'água adaptado a uma régua, em três posições, por três examinadores, sendo os mesmos alunos do $4^{\circ}$. ano do Curso de Graduação em Fisioterapia da Faculdade de Ciências e Tecnologia da UNESP - Campus de Presidente Prudente e a autora da pesquisa, que eram selecionados ao acaso e que não podiam presenciar ou ter conhecimento das medidas realizadas entre eles.

Os examinadores foram orientados para realizarem a mensuração da gibosidade com o nível d'água apoiado horizontalmente ao lado convexo da curva (mantendo a bolha de ar sempre no centro) e no ponto mais elevado da gibosidade, identificava-se a distância até a coluna, em seguida a régua, encaixada no nível d'água, era apoiada perpendicularmente ao lado côncavo da curva usando-se a mesma distância em relação ao lado da gibosidade e então, deslocando-se a régua, se 
necessário, registrava-se (em centímetros) somente o valor da maior gibosidade clínica (FIGURA 3 - A). A gibosidade era classificada em Torácica (direita ou esquerda) ou Lombar (direita ou esquerda).

As mensurações de gibosidade foram realizadas em três posições segundo as orientações de DICKSON \& LEATHERMAN, (1990); DUVALBEAUPÈRE (1992, 1996); SCUTT, DANGERFIELD, DORGAN (1996):

Posição 1- Paciente na posição ortostática com os pés paralelos e afastados aproximadamente $10 \mathrm{~cm}$ e colocados sobre um desenho da impressão plantar com o objetivo de aumentar a base de sustentação e melhorar o equilíbrio. Solicitava-se a flexão do tronco até aproximadamente $90^{\circ}$ com os membros superiores ao longo do corpo livremente (pendurados). A seguir era realizada a mensuração da gibosidade da coluna torácica ou lombar com um nível d'água adaptado a uma régua e registrado somente a maior medida da coluna torácica ou da lombar (FIGURA 3 - B).

Posição 2- Paciente na posição ortostática como na posição 1, com flexão do tronco de aproximadamente $90^{\circ}$ e juntando as palmas das mãos (palma contra palma e dedos contra dedos, simetricamente). A seguir a gibosidade era medida como na posição 1 (FIGURA 3 - C).

Posição 3- Paciente sentado em um banco quadrado com aproximadamente $50 \mathrm{~cm}$ de altura, com o tronco flexionado, impedindo a elevação do quadril do banco, deixando os membros superiores ao lado do corpo e nivelados com o chão e lateralmente aos seus pés. A seguir a gibosidade era medida como na posição 1 (FIGURA 3 - D). 

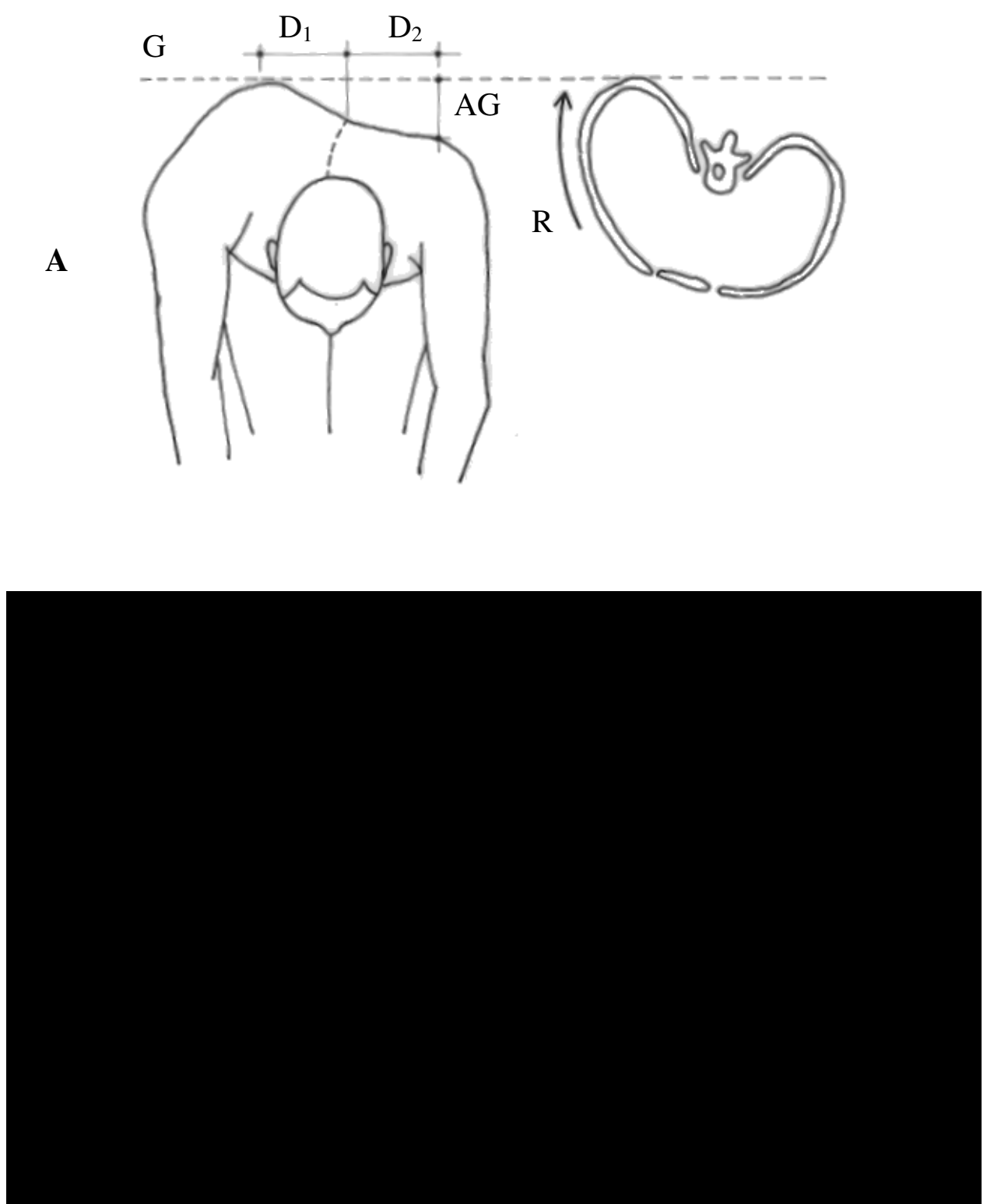

FIGURA 3 - A. Esquema utilizado para medir gibosidade clínica, D1= distância da coluna ao ponto mais alto da gibosidade, D2= mesma distância registrada em D1, $\mathrm{AG}=$ altura da gibosidade, $\mathrm{R}=$ rotação; $\mathbf{B}$. Posição 1 para medir gibosidade com um nível d'água e uma régua; C. Posição 2 para medir gibosidade; D. Posição 3 para medir gibosidade. 


\section{C) Exame radiológico}

Nesse procedimento foram utilizados 2 radiografias, sendo uma ântero-posterior na posição ortostática e outra na posição de decúbito dorsal, de acordo com as normas internacionais de radiologia. Os registros e as mensurações realizados nesses exames foram feitos por uma única pessoa e constaram de:

1- Padrão da curva:

O padrão da curva foi determinado de acordo com a seguinte classificação:

- curva simples: torácica, tóraco-lombar e lombar;

- curva dupla: torácica e lombar, torácica e tóraco-lombar e tóracolombar e lombar;

- curva tripla: apresentava três curvas ao longo da coluna torácica, tóraco-lombar e lombar;

- localização: definida pela localização da vértebra apical da curva (torácica, tóraco-lombar e lombar);

- extensão: definida pela vértebra superior e inferior da curva;

- vértebra apical: identificava a vértebra com maior rotação da curva escoliótica;

- lado da curva: definida pelo lado da convexidade da curva.

2- Medida do ângulo de Cobb:

A curvatura vertebral foi mensurada pelo método de Cobb (DICKSON \& LEATHERMAN, 1988), conforme a padronização da "Scoliosis Research Society" (TERMINOLOGY..., 1976).

3- Medida da rotação vertebral:

A rotação vertebral foi mensurada pelo método de Nash \& Moe (NASH \& MOE, 1969) e pelo método de Raimondi (WEISS, 1995).

No método de Nash \& Moe o grau de rotação vertebral é classificado de Grau I (+) até Grau IV (+ + + +), baseando-se na imagem do pedículo vertebral na radiografia em ântero-posterior (TABELA 2). 
TABELA 2 - Determinação da rotação vertebral pelo método NASH \& MOE.

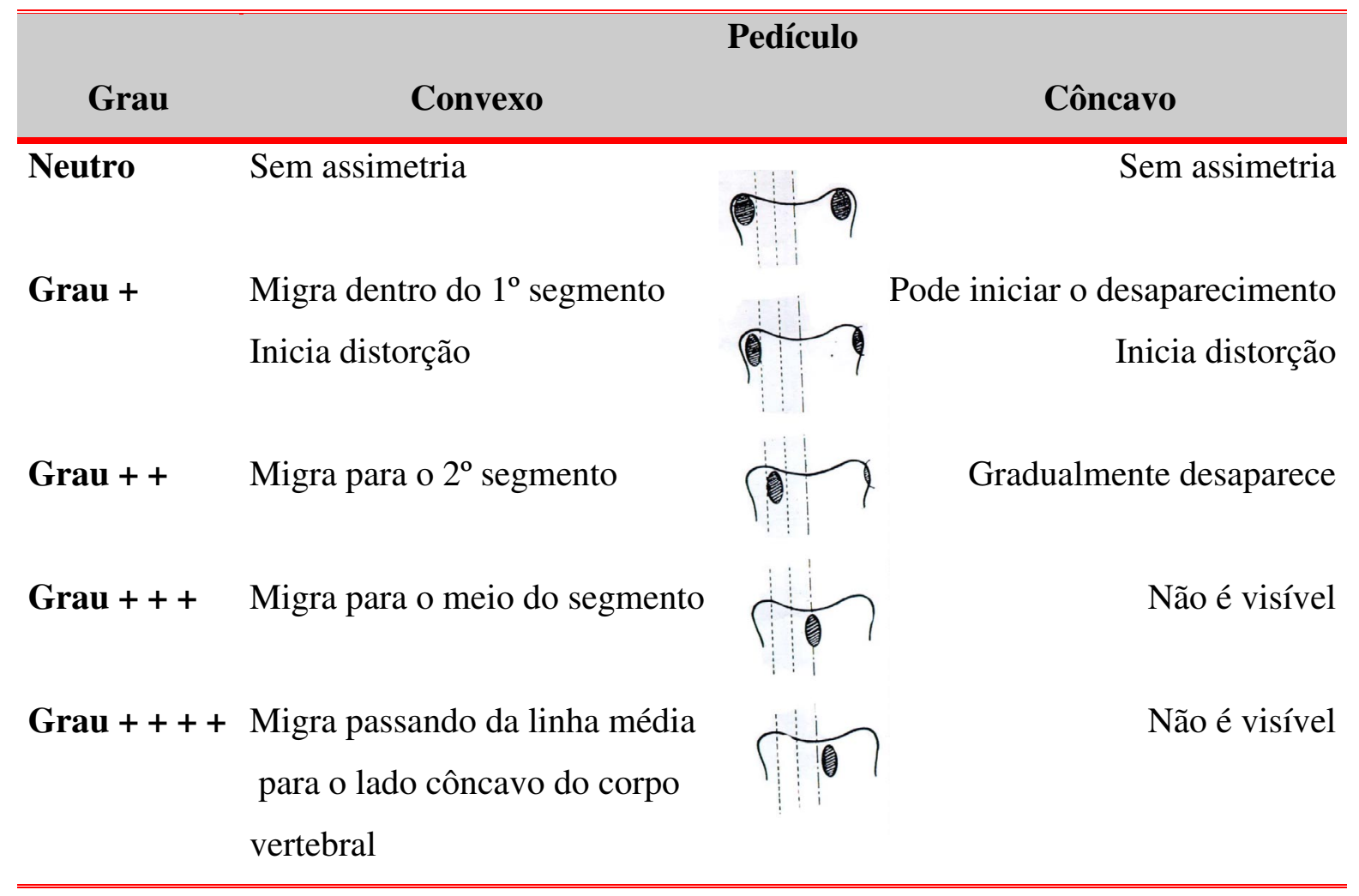

No método de Raimondi como mostra o esquema da FIGURA 4, era medida a largura do corpo vertebral em uma radiografia ântero-posterior no seu ponto mais estreito. O pedículo do lado convexo era dividido ao meio no seu eixo longitudinal. Para determinar a distância pedicular, considerava-se a distância da linha que o dividia ao meio até o lado convexo, no ponto mais estreito do corpo vertebral, sendo essa distância registrada. Depois dessa mensuração, o valor da largura do corpo vertebral obtido anteriormente (em milímetros) era colocado em uma abertura da régua de Raimondi, e o valor da distância pedicular já registrado (em milímetros também) era localizado acima dessa abertura e justamente ao lado desse valor o correspondente grau de rotação vertebral era obtido (WEISS, 1995). 

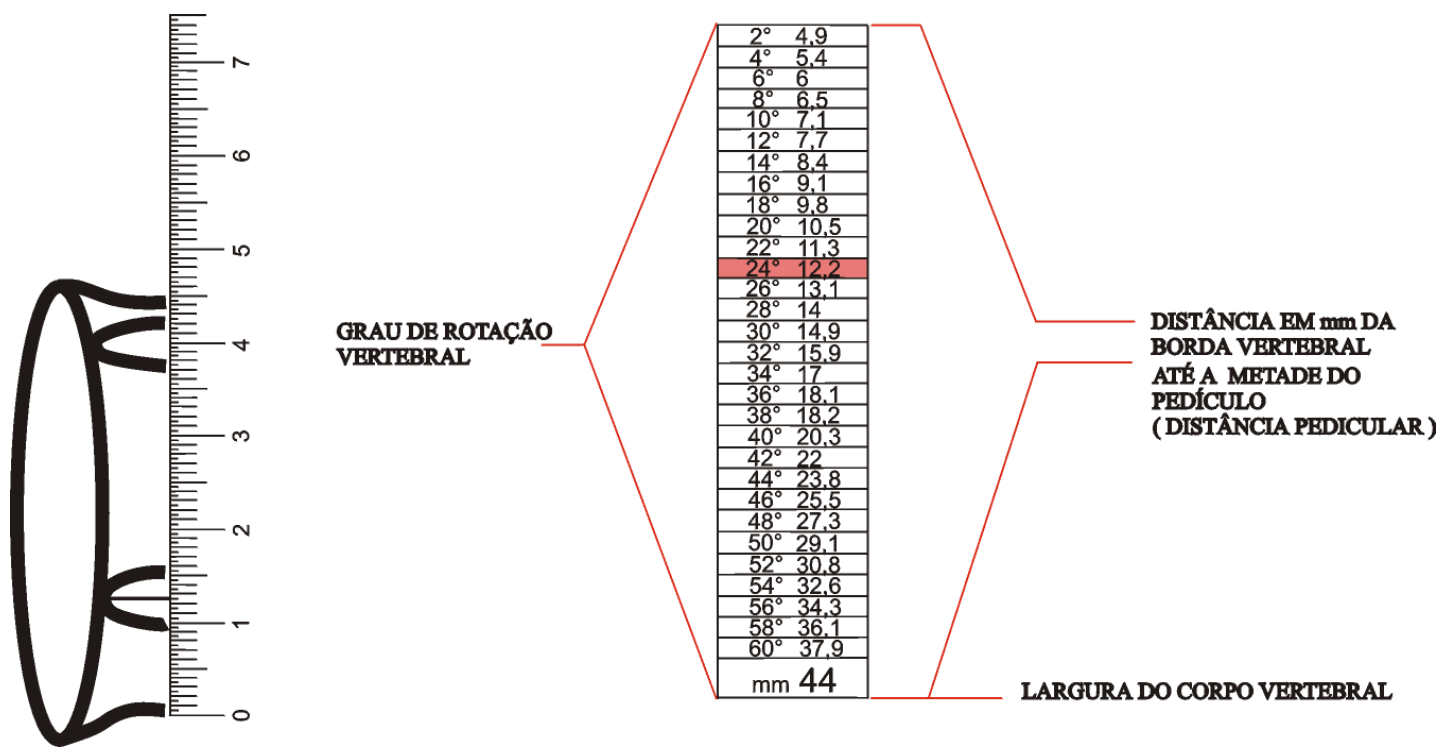

FIGURA 4 - Esquema utilizado para medir rotação vertebral pelo método de Raimondi. O exemplo da figura mostra que a largura do corpo vertebral é de $44 \mathrm{~mm}$, a distância pedicular é de $12 \mathrm{~mm}$ e o valor da rotação vertebral é de 24 graus.

\subsection{Análise estatística dos dados}

Para verificar a existência ou não de uma diferença significativa entre os examinadores, foi aplicado o teste de hipótese (a normalidade e a variabilidade dos dados foi verificada ao nível de 5\%). Para esse caso foi utilizado o teste "t", de "student", em que t é o t crítico, obtido em função $\alpha=5$ e $1 \%$ (nível de significância) com (n-1) graus de liberdade; e o to é o t observado. Como o teste é bilateral (considera-se os valores positivos e negativos), aceita-se Ho se to observado estiver contido na região de aceitação $(-t \leq$ to $\leq \mathrm{t}$ ). Quando no mínimo dois examinadores observavam a mesma gibosidade (torácica ou lombar) na mesma posição, foi feita a comparação entre os examinadores.

Para verificar se existe alguma diferença significativa entre as posições 1,2 e 3 , foi aplicado o teste de hipótese para as medidas de 2 posições correlatas. Para essa análise foi também utilizado o teste "t" de "student" e o nível de significância adotado foi de 5\% (a normalidade e a variabilidade dos dados foi 
verificada ao nível de 5\%). Nesse teste é verificada a diferença entre 2 medidas, ou seja, se existe diferença entre as medidas de gibosidade da posição 1 menos a posição 2, ou da posição 1 menos a posição 3 ou ainda da posição 2 menos a posição 3 . Quando a diferença for igual a zero, as medidas das posições que estão sendo comparadas são iguais, aceitando-se assim a hipótese nula Ho.

A correlação das medidas de gibosidade com as medidas radiológicas do ângulo de Cobb e da rotação vertebral pelos métodos Nash \& Moe e pelo método de Raimondi, na posição ortostática e em decúbito dorsal, foi realizada empregandose o coeficiente de correlação linear de Pearson, que quantifica o relacionamento entre duas variáveis, denotado por $r$. Esse coeficiente pode variar entre -1 e +1 . Com $r=-1$ significa que existe uma correlação linear negativa perfeita; $r=+1$ significa que existe uma correlação linear positiva perfeita, e $r=0$ pode significar apenas que as duas variáveis não estão linearmente correlacionadas.

A correlação das medidas de gibosidade com as medidas radiográficas foram feitas nas três posições, com a medida de um único examinador ou com a média das medidas de dois ou três examinadores, desde que houvesse correlação com as medidas radiológicas, levando-se em conta a região da coluna (torácica, lombar e tóraco-lombar), o lado da gibosidade e do ângulo de Cobb (direito e esquerdo) e a rotação vertebral (vértebra apical).

Nessa pesquisa o coeficiente de correlação de Pearson, também foi usado para correlacionar a medida do ângulo de Cobb com a medida da rotação vertebral pelo método Nash \& Moe e pelo método de Raimondi, na posição ortostática e em decúbito dorsal.

Para comparar a magnitude da curva e da rotação vertebral, mensurada nas radiografias realizadas na posição ortostática e em decúbito dorsal, foi aplicado um teste de hipótese (teste "t") a 5\% de significância, (a normalidade dos dados foi verificada ao nível de 5\%). 


\section{RESULTADOS}

\subsection{Considerações gerais}

Todos os casos de escoliose encaminhados foram avaliados sem critérios de exclusão, pois o interesse era conseguir um número amostral satisfatório, e como um dos objetivos da pesquisa era o de testar a concordância das medidas da gibosidade por vários examinadores e em três posições distintas, era importante realizar a análise com gibosidades de vários tamanhos, tendo em vista que as grandes gibosidades são facilmente visíveis e mensuráveis.

Seis pacientes apresentavam assimetria no comprimento dos membros inferiores constatados por meio do escanograma (obs.: o escanograma foi solicitado apenas aos pacientes que apresentaram diferença no comprimento dos membros inferiores acima de $1 \mathrm{~cm}$ acusada pela medida real realizada com uma fita métrica). Dois pacientes apresentavam $0,3 \mathrm{~cm}$ de encurtamento; dois pacientes com $1,0 \mathrm{~cm}$ de encurtamento; um paciente com 1,2cm e um com 1,6cm de encurtamento.

As medidas de gibosidade foram extraídas dos 52 pacientes por três examinadores em três posições diferentes. As gibosidades torácicas apresentaram extremos de 0,1 a 2,8 $\mathrm{cm}$ e as lombares de 0,1 a 1,8 cm. A TABELA 3 mostra a média e o desvio padrão (SD) dos valores da gibosidade. 
TABELA 3 - Média e desvio padrão (SD) das medidas de gibosidade nas regiões torácica direita e esquerda, e lombar direita e esquerda, realizada nas três posições.

\begin{tabular}{|c|c|c|c|c|c|c|c|c|}
\hline \multirow[t]{2}{*}{ Posições } & \multicolumn{2}{|c|}{$\begin{array}{c}\text { Torácica } \\
\text { Direita }\end{array}$} & \multicolumn{2}{|c|}{$\begin{array}{l}\text { Torácica } \\
\text { Esquerda }\end{array}$} & \multicolumn{2}{|c|}{$\begin{array}{c}\text { Lombar } \\
\text { Direita }\end{array}$} & \multicolumn{2}{|c|}{$\begin{array}{c}\text { Lombar } \\
\text { Esquerda }\end{array}$} \\
\hline & Méd & SD & Méd & SD & Médi & SD & Méd & SD \\
\hline 1 & 0,71 & 0,49 & 0,47 & 0,46 & 0,55 & 0,32 & 0,60 & 0,37 \\
\hline 2 & 0,72 & 0,52 & 0,45 & 0,50 & 0,50 & 0,30 & 0,54 & 0,30 \\
\hline 3 & 0,68 & 0,41 & 0,46 & 0,48 & 0,56 & 0,26 & 0,54 & 0,35 \\
\hline
\end{tabular}

O ângulo de Cobb e a rotação vertebral foram medidos de 48 radiografias em ântero-posterior sendo que 43 na posição ortostática e em decúbito dorsal e cinco só realizaram a radiografia na posição ortostática. A distribuição dos tipos de curvas foram: curvas simples -Torácica $(n=5)$, Tóraco-lombar $(n=14)$ e Lombar $(n=2)$; curvas duplas - Torácica e Tóraco-lombar $(n=16)$, Tóraco-lombar e Lombar $(n=6)$ Torácica e Lombar $(n=3)$; curvas triplas $(n=2)$. Dezoito pacientes apresentavam curvas $<$ que $10^{\circ}$, porém o restante apresentavam curvas $\geq 10^{\circ}$. Os valores da média, desvio padrão e limites destas variáveis estão nas TABELAS 4 e 5.

TABELA 4 - Média, desvio padrão (SD) e limites do ângulo de Cobb nas regiões torácica, lombar e tóraco-lombar direita (D) e esquerda (E).

\begin{tabular}{lrrrrrr}
\hline \hline & \multicolumn{3}{c}{ Ortostática } & \multicolumn{3}{c}{ Decúbito } \\
\cline { 2 - 7 } & Torácica & Lombar & $\begin{array}{l}\text { Tóraco- } \\
\text { lombar }\end{array}$ & Torácica & Lombar & $\begin{array}{l}\text { Tóraco- } \\
\text { lombar }\end{array}$ \\
\hline Média & 13,09 & 10,25 & 11,58 & 8,65 & 5,90 & 7,04 \\
SD & 10,32 & 4,69 & 7,28 & 6,96 & 1,92 & 5,59 \\
Limites & $2,5-47$ & $5-22$ & $3-37$ & $2-35$ & $3-8,5$ & $1-25$ \\
\hline \hline
\end{tabular}


TABELA 5 - Média, desvio padrão (SD) e limites da rotação vertebral pelo método de Raimondi (graus) nas regiões torácica, lombar e tóraco-lombar D e E.

\begin{tabular}{lrrrrrr}
\hline \hline & \multicolumn{3}{c}{ Ortostática } & \multicolumn{3}{c}{ Decúbito } \\
\cline { 2 - 7 } & Torácica & Lombar & $\begin{array}{l}\text { Tóraco- } \\
\text { lombar }\end{array}$ & Torácica & Lombar & $\begin{array}{l}\text { Tóraco- } \\
\text { lombar }\end{array}$ \\
\hline Média & 6,23 & 7,08 & 7,36 & 3,69 & 6,63 & 5,90 \\
SD & 5,31 & 2,67 & 5,33 & 3,81 & 3,00 & 5,53 \\
Limites & $0-23$ & $2-11$ & $0-24$ & $0-18$ & $2-11$ & $0-24$ \\
\hline \hline
\end{tabular}

\subsection{Medidas de gibosidade entre os três examinadores}

A análise utilizada na TABELA 6 , mostra que não existiu diferença significativa aos níveis de 5 e $1 \%$ de significância entre os examinadores nas diferentes posições e nos diferentes tipos de localização da gibosidade (torácica e lombar). Verificando-se, portanto uma alta concordância das medidas de gibosidade entre os três examinadores. 
TABELA 6 - Valores obtidos do resultado do teste de hipótese, nas posições 1, 2 e 3 usando a medida de gibosidade torácica D e E ou lombar D e E, obtida pelos três examinadores.

\begin{tabular}{|c|c|c|c|}
\hline & Posição 1 & Posição 2 & Posição 3 \\
\hline $\begin{array}{c}\text { Torácica } \\
\text { Direita }\end{array}$ & $\begin{array}{c}\mathrm{n}=10 \\
\text { to }=0,30 \\
-3,35 \leq \mathrm{t} \leq 3,35 \\
\text { aceita-se Ho } \\
\text { não há diferença }\end{array}$ & $\begin{array}{c}\mathrm{n}=10 \\
\text { to=0,40 } \\
-3,35 \leq \mathrm{t} \leq 3,35 \\
\text { aceita-se Ho } \\
\text { não há diferença }\end{array}$ & $\begin{array}{c}\mathrm{n}=11 \\
\text { to }=2,82 \\
-3,32 \leq \mathrm{t} \leq 3,32 \\
\text { aceita-se Ho } \\
\text { não há diferença }\end{array}$ \\
\hline $\begin{array}{l}\text { Torácica } \\
\text { Esquerda }\end{array}$ & $\begin{array}{c}\mathrm{n}=6 \\
\text { to }=0,33 \\
-3,68 \leq \mathrm{t} \leq 3,68 \\
\text { aceita-se Ho } \\
\text { não há diferença }\end{array}$ & $\begin{array}{c}\mathrm{n}=5 \\
\text { to= }=1,02 \\
-3,89 \leq \mathrm{t} \leq 3,89 \\
\text { aceita-se Ho } \\
\text { não há diferença }\end{array}$ & $\begin{array}{c}\mathrm{n}=6 \\
\text { to }=0,97 \\
-3,68 \leq \mathrm{t} \leq 3,68 \\
\text { aceita-se Ho } \\
\text { não há diferença }\end{array}$ \\
\hline $\begin{array}{c}\text { Lombar } \\
\text { Direita }\end{array}$ & $\begin{array}{c}\mathrm{n}=8 \\
\text { to }=0,10 \\
-4,60 \leq \mathrm{t} \leq 4,60 \\
\text { aceita-se Ho } \\
\text { não há diferença }\end{array}$ & $\begin{array}{c}\mathrm{n}=7 \\
\text { to=0,18 } \\
-4,75 \leq \mathrm{t} \leq 4,75 \\
\text { aceita-se Ho } \\
\text { não há diferença }\end{array}$ & $\begin{array}{c}\mathrm{n}=7 \\
\text { to }=0,05 \\
-4,75 \leq \mathrm{t} \leq 4,75 \\
\text { aceita-se Ho } \\
\text { não há diferença }\end{array}$ \\
\hline $\begin{array}{l}\text { Lombar } \\
\text { Esquerda }\end{array}$ & $\begin{array}{c}\mathrm{n}=6 \\
\text { to }=0,32 \\
-4,10 \leq \mathrm{t} \leq 4,10 \\
\text { aceita-se Ho } \\
\text { não há diferença }\end{array}$ & $\begin{array}{c}\mathrm{n}=6 \\
\text { to=0,49 } \\
-4,10 \leq \mathrm{t} \leq 4,10 \\
\text { aceita-se Ho } \\
\text { não há diferença }\end{array}$ & $\begin{array}{c}\mathrm{n}=5 \\
\text { to }=0,32 \\
-4,46 \leq \mathrm{t} \leq 4,46 \\
\text { aceita-se Ho } \\
\text { não há diferença }\end{array}$ \\
\hline
\end{tabular}




\subsection{Medidas de gibosidade nas três posições}

$\mathrm{Na}$ análise utilizada na TABELA 7 para verificar se existe alguma diferença significativa entre as posições 1,2 e 3 , temos que $\mathrm{Da}=($ diferença de amplitude das medidas de gibosidade da posição 1 menos a posição 2); $\mathrm{Db}=$ (diferença de amplitude das medidas de gibosidade da posição 1 menos a posição 3) e $\mathrm{Dc}=$ (diferença de amplitude das medidas de gibosidade da posição 2 menos a posição 3).

Observamos que existe diferença significativa da posição 2 com a posição 3, nas gibosidades torácica E e lombar E, pois rejeita-se ao nível de 5\% a hipótese de Ho, enquanto que, para as gibosidades torácica D e lombar D não houve diferença significativa entre as posições, conforme demonstrado na TABELA 7.

Por isso, podemos observar que a posição 1 é a que apresenta maior concordância, pois nas comparações entre as posições 1-2, 1-3 e 2-3, apenas as duas primeiras não apresentaram diferenças significativas, ou seja, quando se compara a posição 1 com as posições 2 e 3 não há diferença significativa, mas quando se compara a posição 2 com a posição 3 , existe diferença significativa . 
TABELA 7 - Valores obtidos do resultado do teste de hipótese, nas posições 1, 2 e 3 usando a amplitude da medida de gibosidade torácica D e E ou lombar D e E, obtida pelos três examinadores.

\begin{tabular}{|c|c|c|c|}
\hline & Da & Db & Dc \\
\hline $\begin{array}{l}\text { Torácica } \\
\text { Direita }\end{array}$ & $\begin{array}{c}\mathrm{n}=18 \\
\text { to }=-0,74 \\
-2,110 \leq \mathrm{t} \leq 2,110 \\
\text { aceita-se Ho } \\
\text { não há diferença }\end{array}$ & $\begin{array}{c}\mathrm{n}=17 \\
\text { to=0,62 } \\
-2,119 \leq \mathrm{t} \leq 2,119 \\
\text { aceita-se Ho } \\
\text { não há diferença }\end{array}$ & $\begin{array}{c}\mathrm{n}=17 \\
\text { to=-0,91 } \\
-2,119 \leq \mathrm{t} \leq 2,119 \\
\text { aceita-se Ho } \\
\text { não há diferença }\end{array}$ \\
\hline $\begin{array}{l}\text { Torácica } \\
\text { Esquerda }\end{array}$ & $\begin{array}{c}\mathrm{n}=8 \\
\text { to }=0,35 \\
-2,365 \leq \mathrm{t} \leq 2,365 \\
\text { aceita-se Ho } \\
\text { não há diferença }\end{array}$ & $\begin{array}{c}\mathrm{n}=8 \\
\text { to }=-1,35 \\
-2,365 \leq \mathrm{t} \leq 2,365 \\
\text { aceita-se Ho } \\
\text { não há diferença }\end{array}$ & $\begin{array}{c}\mathrm{n}=8 \\
\text { to }=-2,51 \\
-2,365 \leq \mathrm{t} \leq 2,365 \\
\text { rejeita-se Ho } \\
\text { há diferença * }\end{array}$ \\
\hline $\begin{array}{c}\text { Lombar } \\
\text { Direita }\end{array}$ & $\begin{array}{c}\mathrm{n}=8 \\
\text { to }=-0,15 \\
-2,365 \leq \mathrm{t} \leq 2,365 \\
\text { aceita-se Ho } \\
\text { não há diferença }\end{array}$ & $\begin{array}{c}\mathrm{n}=8 \\
\text { to }=1,2 \\
-2,365 \leq \mathrm{t} \leq 2,365 \\
\text { aceita-se Ho } \\
\text { não há diferença }\end{array}$ & $\begin{array}{c}\mathrm{n}=8 \\
\text { to }=1,22 \\
-2,365 \leq \mathrm{t} \leq 2,365 \\
\text { aceita-se Ho } \\
\text { não há diferença }\end{array}$ \\
\hline $\begin{array}{l}\text { Lombar } \\
\text { Esquerda }\end{array}$ & $\begin{array}{c}\mathrm{n}=11 \\
\text { to=-1,84 } \\
-2,228 \leq \mathrm{t} \leq 2,228 \\
\text { aceita-se Ho } \\
\text { não há diferença }\end{array}$ & $\begin{array}{c}\mathrm{n}=12 \\
\text { to=0,21 } \\
-2,201 \leq \mathrm{t} \leq 2,201 \\
\text { aceita-se Ho } \\
\text { não há diferença }\end{array}$ & $\begin{array}{c}\mathrm{n}=12 \\
\text { to }=2,53 \\
-2,201 \leq \mathrm{t} \leq 2,201 \\
\text { rejeita-se Ho } \\
\text { há diferença } * *\end{array}$ \\
\hline $\begin{array}{r}\text { Obs.: Quando } \\
\text { mesma } \\
\text { do n to } \\
\text { *Aplicando-se } \\
\text { há dife } \\
\text { **Aplicando-se } \\
\text { permar } \\
2,2281\end{array}$ & $\begin{array}{l}\text { mo } 2 \text { examinadore } \\
\text { o, foi feita a comp } \\
\\
\text { excluindo um pac } \\
\text { gnificante entre as } \\
\text { e excluindo um p } \\
\text { xistindo diferença } \\
\text {-se Ho. }\end{array}$ & $\begin{array}{l}\text { aram a mesma gibc } \\
\text { tre as posições, por } \\
\text { 7), que apresentou } q \\
(\text { to }=2,09)-2,447 \leq t \\
=11) \text { que apresento } \\
\text { inte entre as posiç }\end{array}$ & $\begin{array}{l}\text { orácica ou lombar) na } \\
\text { é variável, diferindo } \\
\text { além do padrão, não } \\
\text { ceita-se Ho. } \\
\text { ade acima do padrão, } \\
-3,35)-2,2281 \leq \mathrm{t} \leq\end{array}$ \\
\hline
\end{tabular}


3.4 Correlação das medidas de gibosidade com as medidas radiológicas na posição ortostática e em decúbito dorsal

As TABELAS 8, 9, e 10, mostram os valores da correlação das medidas de gibosidade com as medidas radiológicas. Segundo a classificação de CICCHETTI \& SPARROW (1981), também citada por MIOR et al. (1996), o coeficiente de correlação pode ser considerado "insatisfatório", quando o valor é menor do que 0,55 (valores em preto); de 0,55 a 0,64 "moderado" (valores em azul); de 0,65 a 0,76 "bom" (valores em verde), e maior do que 0,77 a correlação é considerada "excelente" (valores em vermelho). A correlação também pode ser negativa seguindo a mesma classificação (valores em amarelo).

Os valores da TABELA 8, mostram uma correlação excelente de gibosidade com o ângulo de Cobb para as escolioses torácicas nas posições 1 e 2 em ortostático e em decúbito ( $\mathrm{r}=0,90, \mathrm{r}={ }^{*} 0,91$, FIGURA 5 e $\mathrm{r}=0,84, \mathrm{r}=0,86$, respectivamente), enquanto que na posição 3 em ortostático a correlação foi moderada $(r=0,60)$ e os demais valores são considerados insatisfatórios. Observa-se um valor de correlação negativa $(\mathrm{r}=-0.05)$ nas curvas lombares na posição $3 \mathrm{em}$ ortostático.

TABELA 8 - Correlação da medida da gibosidade $(\mathrm{cm})$ realizada nas três posições com o ângulo de Cobb (graus) na posição ortostática e decúbito nas escolioses torácica, lombar e tóraco-lombar D e E

\begin{tabular}{crrrrrr}
\hline \hline $\begin{array}{c}\text { Curvas } \\
\text { Posições }\end{array}$ & Torácica & Lombar & $\begin{array}{l}\text { Tóraco- } \\
\text { lombar }\end{array}$ & Torácica & Lombar & $\begin{array}{l}\text { Tóraco- } \\
\text { lombar }\end{array}$ \\
\hline $\mathbf{1}$ & 0,90 & 0,33 & 0,18 & 0,84 & 0,43 & 0,22 \\
$\mathbf{2}$ & $* 0,91$ & 0,37 & 0,18 & 0,86 & 0,45 & 0,21 \\
$\mathbf{3}$ & 0,60 & $-0,05$ & 0,17 & 0,54 & 0,04 & 0,35 \\
\hline \hline
\end{tabular}

* FIGURA 5 


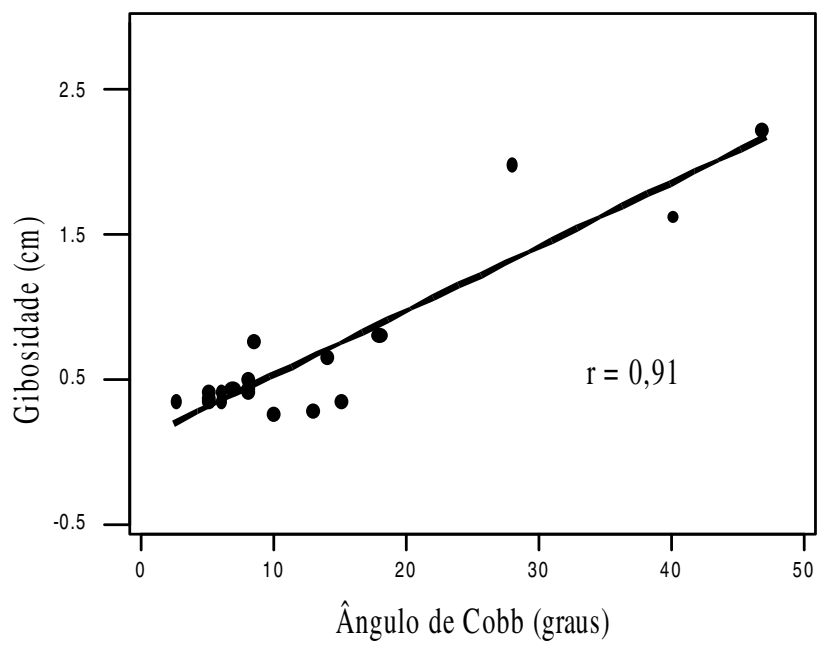

FIGURA 5 - Reta de regressão obtida da correlação da medida de gibosidade $(\mathrm{cm})$ na posição 2 com o ângulo de Cobb (graus) na posição ortostática nas escolioses torácicas D e E.

Na TABELA 9 observamos que a correlação foi excelente da gibosidade com a rotação vertebral pelo método de Raimondi para as curvas torácicas na posição 1 e 2 em ortostático $(r=0,85)$ e nas curvas lombares na posição 1 em decúbito $(\mathrm{r}=0,78)$; nas curvas torácicas nas posições 1 e 2 em decúbito a correlação foi considerada boa ( $\mathrm{r}=0,69$ e $\mathrm{r}=0,71$, respectivamente); nas curvas lombares nas posições 2 e 3 em decúbito foi moderada ( $r=0,55$ e r=0,56, respectivamente) e os demais valores são insatisfatórios ( $r=* 0,10$, FIGURA 6). 
TABELA 9 - Correlação da medida de gibosidade $(\mathrm{cm})$ realizada nas três posições com a rotação vertebral pelo método de Raimondi (graus) na posição ortostática e decúbito nas escolioses torácica, lombar e tóraco-lombar D e E.

\begin{tabular}{crrrrrr}
\hline \hline $\begin{array}{c}\text { Curvas } \\
\text { Posições }\end{array}$ & \multicolumn{3}{c}{ Ortostática } & \multicolumn{3}{c}{ Decúbito } \\
\cline { 2 - 8 } & Torácica & Lombar & $\begin{array}{l}\text { Tóraco- } \\
\text { lombar }\end{array}$ & Torácica & Lombar & $\begin{array}{l}\text { Tóraco- } \\
\text { lombar }\end{array}$ \\
\hline $\mathbf{1}$ & 0,85 & 0,45 & 0,33 & 0,69 & 0,78 & 0,18 \\
$\mathbf{2}$ & 0,85 & 0,21 & 0,38 & 0,71 & 0,55 & 0,28 \\
$\mathbf{3}$ & 0,44 & 0,05 & 0,11 & 0,45 & 0,56 & $* 0,10$ \\
\hline \hline * FIGURA 6 & & & & & &
\end{tabular}

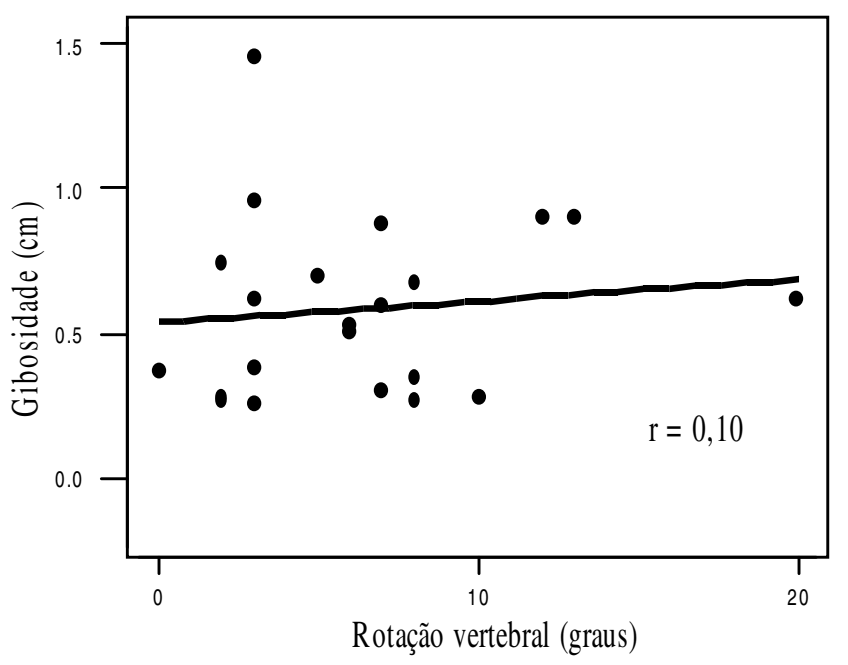

FIGURA 6 - Reta de regressão obtida da correlação da medida de gibosidade $(\mathrm{cm})$ na posição 3 com a rotação vertebral pelo método de Raimondi (graus) na posição de decúbito nas escolioses tóraco-lombares D e E.

A Tabela 10 mostra apenas valores de correlação boa da gibosidade com a rotação vertebral pelo método Nash \& Moe para as curvas torácicas nas posições 1 e 2 em ortostático ( $r=* 0,77$, FIGURA 7 e $r=0,74$, respectivamente); os demais valores são insatisfatórios e com valores negativos para as curvas lombares nas posições 2 e 3 em ortostático ( $r=-0,05$ e $r=-0,03$, respectivamente). 
TABELA 10 - Correlação da medida de gibosidade $(\mathrm{cm})$ realizada nas três posições com a rotação vertebral pelo método Nash \& Moe (graduação +) na posição ortostática e decúbito nas escolioses torácica, lombar e tóracolombar D e E.

\begin{tabular}{crrrrrr}
\hline \hline \multirow{2}{*}{$\begin{array}{c}\text { Curvas } \\
\text { Posições }\end{array}$} & Torácica & Lombar & $\begin{array}{l}\text { Tóraco- } \\
\text { lombar }\end{array}$ & Torácica & Lombar & $\begin{array}{l}\text { Tóraco- } \\
\text { lombar }\end{array}$ \\
\hline $\mathbf{1}$ & $* 0,77$ & 0,11 & 0,48 & 0,45 & 0,32 & 0,38 \\
$\mathbf{2}$ & 0,74 & $-0,05$ & 0,49 & 0,46 & 0,10 & 0,44 \\
$\mathbf{3}$ & 0,50 & $-0,03$ & 0,22 & 0,15 & 0,20 & 0,35 \\
\hline \hline * FIGURA 7 & & & & & &
\end{tabular}

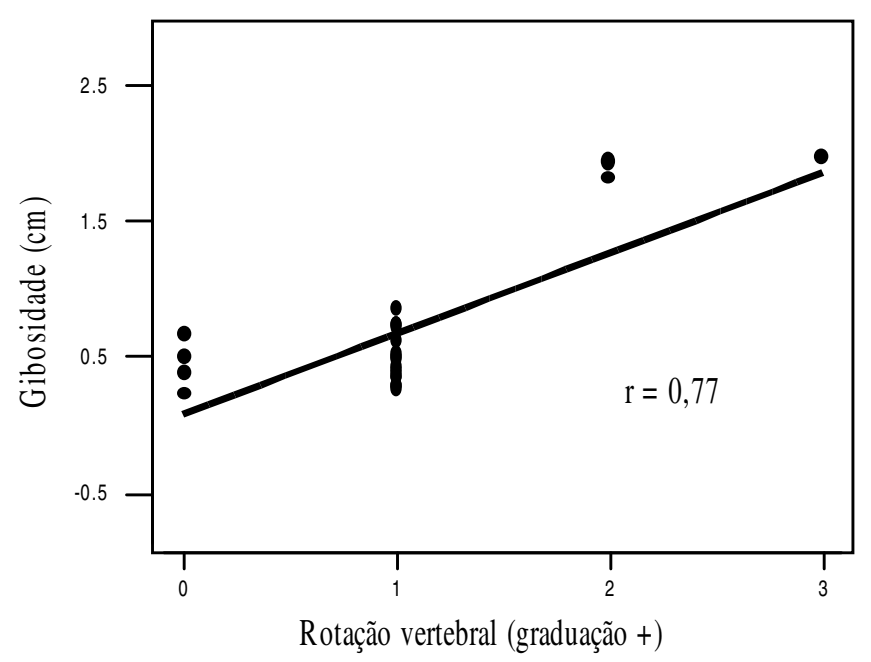

FIGURA 7 - Reta de regressão obtida da correlação da medida de gibosidade $(\mathrm{cm})$ na posição 1 com a rotação vertebral pelo método Nash \& Moe (graduação +) na posição ortostática nas escolioses torácicas D e E. 
3.5 Correlação das medidas do ângulo de Cobb com a rotação vertebral pelo método Nash \& Moe e pelo método de Raimondi na posição ortostática e em decúbito dorsal

A TABELA 11 mostra que o coeficiente de correlação do ângulo de Cobb com a rotação vertebral pelo método de Raimondi foi excelente apenas nas curvas torácicas $(\mathrm{r}=0,90)$, foi bom para as curvas tóraco-lombares na posição ortostática $(\mathrm{r}=0,66)$ e em decúbito foi bom para as curvas torácicas $(\mathrm{r}=0,72)$ e moderado para as curvas tóraco-lombares $(\mathrm{r}=0,57)$, porém, aparece um índice negativo nas curvas lombares ( $\mathrm{r}=*_{-}-0,27$, FIGURA 8); pelo método Nash \& Moe a correlação foi apenas boa nas curvas torácicas em ortostático $(r=0,65)$ e os demais valores foram insatisfatórios.

TABELA 11 - Correlação do ângulo de Cobb (graus) com a rotação vetebral pelo método de Raimondi (graus) e pelo método Nash \& Moe (graduação +) na posição ortostática e decúbito nas escolioses torácica, lombar e tóraco-lombar D e E.

\begin{tabular}{|c|c|c|c|c|c|c|}
\hline \multirow[b]{2}{*}{$\begin{array}{l}\quad \text { Curvas } \\
\text { Rotação } \\
\text { vertebral }\end{array}$} & \multicolumn{3}{|c|}{ Ortostática } & \multicolumn{3}{|c|}{ Decúbito } \\
\hline & Torácica & Lombar & $\begin{array}{l}\text { Tóraco- } \\
\text { lombar }\end{array}$ & Torácica & Lombar & $\begin{array}{l}\text { Tóraco- } \\
\text { lombar }\end{array}$ \\
\hline Raimondi & 0,90 & $-0,27$ & 0,66 & 0,72 & 0,16 & 0,57 \\
\hline $\begin{array}{c}\text { Nash \& } \\
\text { Moe }\end{array}$ & 0,65 & 0,18 & 0,32 & 0,40 & 0,41 & 0,33 \\
\hline
\end{tabular}




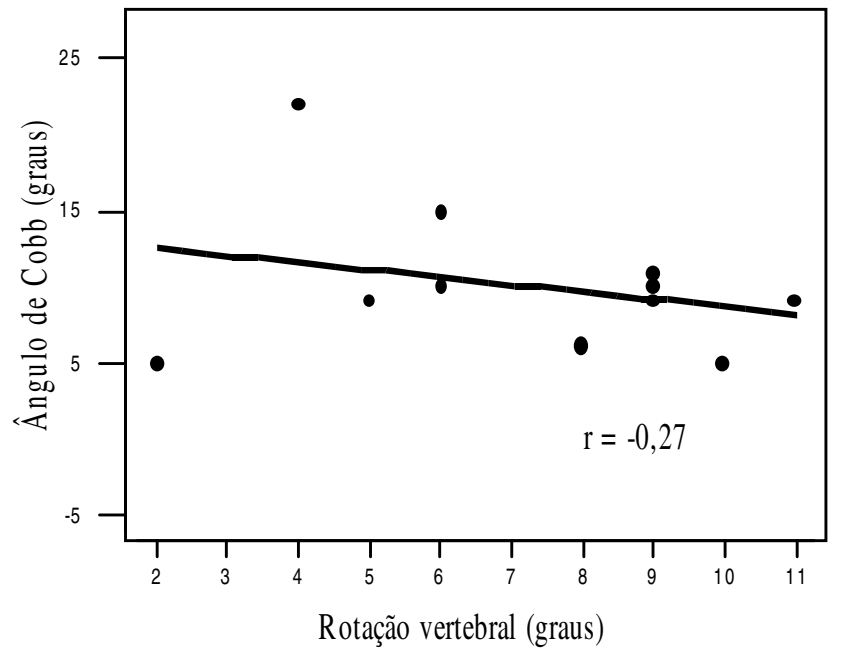

FIGURA 8 - Reta de regressão obtida da correlação da medida do ângulo de Cobb (graus) com a rotação vertebral pelo método de Raimondi (graus) na posição ortostática nas escolioses lombares D e E. 


\subsection{Comparação da magnitude da curva e da rotação vertebral,} mensurada nas radiografias na posição ortostática e em decúbito dorsal

O teste de hipótese indicou uma diferença significativa, aos níveis de $5 \%$, da medida da magnitude da curva pelo ângulo de Cobb, quando se comparou nas radiografias a posição ortostática com a de decúbito dorsal, para todos os tipos de curvas escolióticas, como pode ser constatado na TABELA 12.

TABELA 12 - Resultados do teste de hipótese obtidos pela comparação entre as medidas do ângulo de Cobb (graus) na posição ortostática e decúbito nas escolioses torácica, lombar e tóraco-lombar D e E.

\begin{tabular}{cccc}
\hline \hline & \multicolumn{2}{c}{ Ângulo de Cobb } & \\
\cline { 2 - 4 } & Torácica & Lombar & Tóraco-lombar \\
\hline \multirow{2}{*}{ Ortostático } & $\mathrm{n}=23$ & $\mathrm{n}=10$ & $\mathrm{n}=32$ \\
$\mathbf{x}$ & to $=-4,02$ & to $=-5,36$ & to $=-6,34$ \\
Decúbito & $-2,080 \leq \mathrm{t} \leq 2,080$ & $-2,262 \leq \mathrm{t} \leq 2,262$ & $-2,038 \leq \mathrm{t} \leq 2,038$ \\
& rejeita Ho & rejeita Ho & rejeita Ho \\
& há diferença & há diferença & há diferença
\end{tabular}

Obs.: O n é variável pois alguns pacientes apresentavam dupla ou tripla curva, portanto, diferindo do $\mathrm{n}$ total.

A TABELA 13 mostra que existe diferença significativa das medidas de rotação vertebral pelos métodos Raimondi e Nash \& Moe nas escolioses torácica e tóraco-lombar quando se compara a posição ortostática com a de decúbito, porém, nas escolioses lombares não há diferença. 
TABELA 13 - Resultados do teste de hipótese obtidos pela comparação entre as medidas da rotação vertebral pelo método de Raimondi (graus) e pelo método Nash \& Moe (graduação +) na posição ortostática e decúbito nas escolioses torácica, lombar e tóraco-lombar D e E.

\begin{tabular}{|c|c|c|c|}
\hline & \multicolumn{3}{|c|}{ Rotação vertebral - Ortostático/ Decúbito } \\
\hline & Torácica & Lombar & Tóraco-lombar \\
\hline Raimondi & $\begin{array}{c}\mathrm{n}=19 \\
\text { to }=-2,69 \\
-2,101 \leq \mathrm{t} \leq 2,101 \\
\text { rejeita Ho } \\
\text { há diferença }\end{array}$ & $\begin{array}{c}\mathrm{n}=9 \\
\text { to }=-1,89 \\
-2,306 \leq \mathrm{t} \leq 2,306 \\
\text { aceita Ho } \\
\text { não há diferença }\end{array}$ & $\begin{array}{c}\mathrm{n}=26 \\
\text { to }=-3,27 \\
-2,060 \leq \mathrm{t} \leq 2,060 \\
\text { rejeita Ho } \\
\text { há diferença }\end{array}$ \\
\hline Nash \& Moe & $\begin{array}{c}\mathrm{n}=20 \\
\text { to }=-2,52 \\
-2,093 \leq \mathrm{t} \leq 2,093 \\
\text { rejeita Ho } \\
\text { há diferença }\end{array}$ & $\begin{array}{c}\mathrm{n}=9 \\
\text { Todos os valores são } \\
\text { idênticos } \\
\text { aceita Ho } \\
\text { não há diferença }\end{array}$ & $\begin{array}{c}\mathrm{n}=28 \\
\text { to }=-3,10 \\
-2,052 \leq \mathrm{t} \leq 2,052 \\
\text { rejeita Ho } \\
\text { há diferença }\end{array}$ \\
\hline
\end{tabular}

Obs.: O n é variável pois alguns pacientes apresentavam dupla ou tripla curva, portanto, diferindo do $\mathrm{n}$ total. 


\section{DISCUSSÃO}

A expressão das deformidades na superfície do tronco, ou seja, a gibosidade torácica e lombar, com as deformidades anatômicas devido a rotação dos corpos vertebrais, da caixa torácica e o desvio lateral, que acompanham a escoliose idiopática são assuntos amplamente abordados em estudos, porém o seu entendimento não está totalmente definido (ARKIN, 1950; STOKES, ARMSTRONG, MORELAND, 1988; STOKES \& MORELAND, 1989; STOKES \& GARDNER-MORSE, 1991; CLOSKEY \& SCHULTZ, 1993). As mensurações de gibosidade nem sempre apresentam uma boa correlação com as medidas radiológicas, isto implica em dizer que uma gibosidade mínima de $0,5 \mathrm{~cm}$, segundo SOUCACOS et al. (1997), não necessariamente estará relacionada com uma rotação vertebral ou desvio lateral também mínimos.

As gibosidades menores quando detectadas precocemente e de maneira segura por métodos não invasivos, por meio de mensurações periódicas intercaladas com medidas radiológicas, de acordo com critérios médicos, podem fornecer um dado importante para a evolução da escoliose. BUNNELL \& DELAWARE (1984), enfatizaram esta questão quando declararam que estas deformidades, clinicamente insignificantes, são facilmente detectáveis por avaliação individual, portanto, a necessidade de definir uma deformidade significante mínima tem se tornado óbvia.

A importância de intercalar medidas não invasivas entre medidas radiológicas é realizada com o objetivo de se obter um bom parâmetro quantitativo de acompanhamento das escolioses sem expor os pacientes aos riscos decorrentes da radiação excessiva (NASH et al., 1979; ARDRAN et al.,1980; KOGUTT, WARREN, KALMAR, 1989). 
Quando investigadores estudam a precisão de mensurações existem três possibilidades de fontes de variabilidade que devem ser consideradas e que são: variabilidade do paciente, do procedimento e do examinador clínico. As condições de mensuração devem simular a situação clínica tão cuidadosamente quanto possível. Se a precisão for insatisfatória, o investigador deve estar pronto para descobrir a fonte ou fontes de erro e corrigi-las (WRIGHT \& FEINSTEIN, 1992).

Os valores médios de gibosidade observados nessa pesquisa (TABELA 3) mostram que as escolioses estudadas podem, na sua maioria, ser consideradas deformidades estruturais pois mediam $0,5 \mathrm{~cm}$ ou mais e correspondem aproximadamente aos valores das pesquisas de VERCAUTEREN et al. (1982), que observaram que valores de gibosidade torácica e lombar acima de $0,8 \mathrm{~cm}$ e $0,5 \mathrm{~cm}$, respectivamente, são considerados "assimetrias estruturais". A pesquisa de BURWELL et al. (1982), mostrou que em crianças de 8 a 15 anos não havia evidência clínica de escoliose estrutural com valores de gibosidade direita entre 0,22 e $0,65 \mathrm{~cm}$ e esquerda de 0,22 e $0,45 \mathrm{~cm}$. DUVAL-BEAUPÈRE \& LAMIREAU (1985), encontraram um valor médio de gibosidade torácica e lombar de $0,66 \mathrm{~cm}$ $(\mathrm{SD}=0,64 \mathrm{~cm})$ quando mensurado na posição sentada. Para NISSINEN et al. (1989, 1993) os valores de gibosidade acima de $0,6 \mathrm{~cm}$ poderiam indicar uma escoliose de $10^{\circ}$ ou mais. SOUCACOS et al. (1997), consideravam um resultado positivo para escoliose estrutural quando a gibosidade era maior que $0,5 \mathrm{~cm}$ na região torácica e tóraco-lombar e o ângulo de Cobb como sendo $\geq 10^{\circ}$.

Nessa pesquisa o instrumento usado para medir o ângulo de Cobb e a rotação vertebral foi o mesmo e uma única pessoa realizou todas as medidas radiológicas, e segundo SHEA et al. (1998), quando as mensurações são realizadas sob ótimas condições as chances de erro são menores e ainda acrescentam que as vantagens do uso do método de mensuração manual do ângulo de Cobb incluem a facilidade para realizá-lo sobre radiografias padrão e as desvantagens seriam a grande variação do erro intrínseco secundária ao uso inadequado do instrumento ou a utilização de vários instrumentos ou pessoas para realizar estas medidas.

As TABELAS 4 e 5 mostraram os valores médios das medidas radiológicas do ângulo de Cobb na posição ortostática superior a $10^{\circ}$, portanto caracterizando como escoliose do tipo estrutural (NISSINEN et al., 1989; 
PEARSALL, REID, HEDDEN, 1992; NISSINEN et al., 1993; KOROVESSIS \& STAMATAKIS, 1996; HUANG, 1997; SOUCACOS et al., 1997). Os valores do ângulo de Cobb são menores na posição de decúbito dorsal, e segundo KISNER \& COLBY (1987) a curva escoliótica tende a desaparecer na escoliose não-estrutural ou funcional quando o paciente fica em decúbito dorsal. Para os valores de rotação vertebral o decréscimo na posição de decúbito foi menor e os limites praticamente não sofreram alterações.

Estudos sobre a variação da medida do ângulo de Cobb mostram valores de erro intrínseco que se estendem de 2 até $10^{\circ}$ (JEFFRIES et al., 1980; CARMAN, BROWNE, BIRCH, 1990; MORRISSY et al., 1990; BEAUCHAMP et al., 1993; SHEA et al., 1998). Os métodos baseados na sombra dos pedículos para mensuração da rotação vertebral podem ter uma exatidão de aproximadamente $5^{\circ}$, podendo melhorar se a rotação for menor do que $40^{\circ}$ (SKALLI, LAVASTE, DESCRIMES, 1995).

A comparação das medidas de gibosidade entre os examinadores foi realizada nessa pesquisa (TABELA 6) e mostrou que não houve diferença significativa de medidas quando realizada por vários examinadores tanto para gibosidades torácicas como para lombares. As medidas foram feitas com um mesmo instrumento e os examinadores não tinham conhecimento das medidas tomadas entre eles. Portanto, o instrumento usado demostrou uma alta concordância entre os examinadores. AMENDT et al. (1990); MURRELL et al. (1993); SCUTT, DANGERFIELD, DORGAN, (1996); CÔTÉ et al. (1998), também testaram a precisão de métodos não invasivos para mensurar gibosidade e os resultados mostraram alta concordância entre as medidas quando realizadas por vários examinadores, o que permite uma monitoração segura por diferentes terapeutas.

Embora não houvesse diferença significativa entre os examinadores, várias pesquisas (AMENDT et al., 1990; CARMAN, BROWNE, BIRCH, 1990; MORRISSY et al., 1990; BEAUCHAMP et al., 1993; MURRELL et al., 1993; KOROVESIS \& STAMATAKIS, 1996; MIOR et al., 1996; D'OSUALDO, SCHIERANO, IANNIS, 1997; CÔTÉ et al., 1998; SHEA et al., 1998), relatavam a definição dos examinadores, ou seja, eles sempre eram os mesmos e avaliavam na mesma ordem e em alguns casos eram classificados de acordo com o nível de 
experiência clínica. Os examinadores no presente estudo foram selecionados ao acaso e apesar de haver um com maior experiência clínica os resultados não mostraram variação entre eles.

Para medir gibosidade clínica a posição de flexão anterior de tronco ou teste de Adams foi usada em várias pesquisas (THULBOURNE \& GILLESPIE, 1976; BURWELL et al., 1982,1983; VERCAUTEREN et al., 1982; BUNNELL \& DELAWARE, 1984; VIVIANI et al. 1984; DUVAL-BEAUPÈRE \& LAMIREAU, 1985; STOKES \& MORELAND, 1987; NISSINEN et al., 1989; AMENDT et al., 1990; DUVAL-BEAUPÈRE, 1992; PEARSALL, REID, HEDDEN, 1992; BUNNELL, 1993; MURRELL et al., 1993; NISSINEN et al., 1993; THEOLOGIS et al., 1993; DUVAL-BEAUPÈRE, 1996; KOROVESIS \& STAMATAKIS, 1996; SCUTT, DANGERFIELD, DORGAN, 1996; HUANG, 1997; SOUCACOS et al., 1997; CÔTÉ et al, 1998), porém com muitas variações, como a inclinação anterior com as mãos pendentes e livres ao longo do corpo, ou mãos unidas, ou ainda com as mãos unidas e colocadas entre os joelhos; a posição sentada com inclinação anterior ou de decúbito ventral também foram usadas por alguns dos autores citados acima.

A posição padrão do teste de Adams, segundo DICKSON \& LEATHERMAN (1988), é com os pés juntos, joelhos estendidos, ombros livres e mãos posicionadas entre os joelhos ou pernas, com os cotovelos retos e palma das mãos em oposição, porém quando existe diferença do comprimento dos membros superiores a medida pode se alterar nesta posição, por isso os autores sugerem também a posição de inclinação anterior com os membros superiores livres, mas acrescentam que o importante na posição utilizada no teste é descrevê-la acuradamente, pois desta forma os resultados serão menos questionados.

A comparação das três posições utilizadas nessa pesquisa foi realizada inclusive com o uso da posição sentada para excluir as escolioses por desigualdade do comprimento dos membros inferiores ou assimetrias da pelve (BURWELL et al., 1983; DUVAL-BEAUPÈRE, 1992) e segundo VERCAUTEREN et al. (1982); HOIKKA, ILIKOSHI, TALLROTH, (1989) uma assimetria dos membros inferiores ou da pelve de $1,5 \mathrm{~cm}$ pode ser considerada fisiológica. A impressão plantar também foi utilizada para padronizar a medida, pois segundo WRIGHT \& FEINSTEIN (1992), para reduzir a variabilidade nos procedimentos o método operacional deve 
ser descrito com suficientes detalhes para permitir a reaplicação da técnica e um equipamento similar ou idêntico deve ser usado, bem como moldes desenhados para padronizar a posição dos membros.

A TABELA 7 mostra que quando se compara a posição 3 (sentada) com a posição 2 (flexão anterior com as mãos juntas) existi diferença significativa entre elas mas somente nas curvas para o lado esquerdo, e também observamos que há uma melhor concordância quando se compara a posição 1 (flexão anterior com os membros superiores livres) com a posição 2 e com a posição 3 , portanto a posição 1 é a única que não apresenta diferença significativa em relação as outras posições, o que nos leva a crer que ela seria a posição com menor variação e mais confiável para medir gibosidade clínica.

STOKES \& MORELAND (1987), mediram o formato da superfície do tronco por meio da raster-estereofotografia em três posições (na posição ortostática, na posição de flexão anterior com as mãos entre os joelhos e na posição de flexão anterior com as mãos tocando os dedos do pé). A quantidade de rotação na superfície do tronco era similar em ambas posições de flexão anterior e o valor da correlação com o ângulo de Cobb não foi substancialmente alterado nas três posições.

SCUTT, DANGERFIELD, DORGAN (1996), também mediram gibosidade em três posições (na posição ortostática com flexão anterior, na posição sentada com flexão anterior e em decúbito ventral), porém os autores relatam que a posição deve ser padronizada, tomando-se cuidado para que a cabeça esteja voltada para o mesmo lado durante a medida, e acrescentam que se a comparação não indica concordância mais análises devem ser conduzidas para verificar se a posição do corpo afeta a magnitude da deformidade na superfície. A posição de decúbito ventral apresentou melhor correlação com as medidas radiológicas.

GRAM \& HASAN (1999), também observaram que a posição sentada relaxada diminuia o ápice do ângulo tridimensional e frontal de curvas lombares mas aumentava na posição sentada escrevendo, mostrando que diferentes posições alteram diferentemente os ângulos das curvas nas escolioses idiopáticas.

Os resultados dessa pesquisa concordam com a posição padrão do teste de Adams com as modificações sugeridas por DICKSON \& LEATHERMAN 
(1988) e quando há diferença no comprimento dos membros inferiores além de $1 \mathrm{~cm}$, o escanograma deve ser solicitado para confirmação e providências necessárias para cada caso.

Várias pesquisas testaram a precisão de medidas não invasivas na escoliose por meio da correlação com medidas radiológicas padrão do ângulo de Cobb e da rotação vertebral; a seguir os dados apresentados servirão para comparar os valores dessas correlações com os valores encontrados no presente estudo.

THULBOURNE \& GILLESPIE (1976), relatam que nenhuma relação linear clara foi encontrada nas medidas de gibosidade, usando um instrumento de contorno do tronco, com medidas radiológicas do ângulo de Cobb, da rotação vertebral pelo método Nash \& Moe e do ângulo costo-vertebral (MEHTA, 1972) na posição ortostática. BURWELL et al., (1983) usando o mesmo instrumento obtiveram uma correlação de $r=0,42$ com o ângulo de Cobb e $r=0,35$ com a rotação vertebral usando o torsiômetro. PEARSALL, REID, HEDDEN (1992), também usaram o aparelho de contorno do tronco, e a correlação com o ângulo de Cobb foi boa somente para a região torácica $(r=0,70)$ e na região lombar foi insatisfatória $(\mathrm{r}=0,17)$.

A correlação da medida de gibosidade com o ângulo de Cobb e com a rotação vertebral na posição ortostática, usando o escoliômetro, tem mostrado valores de $\mathrm{r}=0,88$ (BUNNELL \& DELAWARE, 1984); $\mathrm{r}=0,46$ - 0,54 com o ângulo de Cobb e com a rotação vertebral pelo método Nash \& Moe obteve extremos de $\mathrm{r}=0,32$ a 0,46 (AMENDT et al., 1990); $\mathrm{r}=0,59$ para a região torácica e $\mathrm{r}=0,20$ para a região lombar (PEARSALL, REID, HEDDEN, 1992); r=0,41 para a região torácica e $\mathrm{r}=0,64$ para a região lombar (KOROVESIS \& STAMATAKIS, 1996); r=0,74 e $\mathrm{r}=0,66$ para ambos componentes torácico e lombar de duplas curvas, sendo que a medida da gibosidade só demostrou significante correlação na posição prona (SCUTT, DANGERFIELD, DORGAN, 1996).

DUVAL-BEAUPÈRE \& LAMIREAU (1985), estudaram a evolução da escoliose por meio da correlação de medidas de gibosidade, em centímetros, com um nível d' água e uma régua, na posição sentada, com o ângulo de Cobb em ortostático e em decúbito dorsal. A correlação foi de $\mathrm{r}=0,54$ para o ângulo de Cobb 
em decúbito dorsal e $\mathrm{r}=0,45$ em ortostático. Mas para curvas lombares não existiu relação entre gibosidade e evolução da escoliose.

NISSINEN et al. (1989), usaram um nível d'água e uma régua para medir gibosidade, um inclinômetro para medir o ângulo de rotação do tronco em graus e a técnica topográfica de Moiré. A correlação da gibosidade com o ângulo de rotação do tronco foi de $\mathrm{r}=0,74$; da gibosidade com o ângulo de Cobb $(\mathrm{r}=0,20)$; da gibosidade com a técnica de Moiré $(\mathrm{r}=0,16)$ em curvas torácicas baixas; e da técnica de Moiré com o ângulo de Cobb ( $\mathrm{r}=0,14)$.

STOKES \& MORELAND (1989) correlacionaram a topografia de Moiré ( $\mathrm{r}=0,70$ na região superior e $\mathrm{r}=0,77$ na região inferior) com o ângulo de Cobb. PEARSALL, REID, HEDDEN (1992), também usaram a imagem topográfica de Moiré, para correlacionar com o ângulo de Cobb na região torácica $(r=0,80)$ e na região lombar $(\mathrm{r}=0,42)$.

DUVAL-BEAUPÈRE (1992), correlacionou o índice de progressão da escoliose com gibosidade e com o ângulo de Cobb em decúbito dorsal e obteve os seguintes índices: $\mathrm{r}=0,52$ e $\mathrm{r}=0,59$, respectivamente. O mesmo autor em 1996, observou $r=0,68, r=0,68$ e r=0,56 respectivamente, para ângulo de Cobb em decúbito dorsal, ângulo de Cobb em ortostático e gibosidade quando correlacionados com a progressão da escoliose.

A análise de correlação por técnicas de raster-estereofotografia e estereoradiográficas foi usada por vários autores (STOKES, BIGALOW, MORELAND, 1987; STOKES \& MORELAND, 1987; STOKES, ARMSTRONG, MORELAND, 1988; STOKES, 1989; STOKES, DANSEREAU, MORELAND, 1989; STOKES \& MORELAND, 1989; STOKES, 1991) e os valores obtidos nessas pesquisas mostraram extremos de $\mathrm{r}=-0,81$ a $\mathrm{r}=0,98$ quando realizavam a correlação de medidas da deformidade na superfície do tronco com o desvio lateral ou com a rotação vertebral pelo método STOKES, BIGALOW, MORELAND (1986).

TURNER-SMITH et al. (1988), estudaram a correlação da assimetria lateral pela técnica ISIS com o ângulo de Cobb na escoliose idiopática $(r=0,80)$ e na escoliose idiopática do adolescente $(\mathrm{r}=0,77)$, para todos os tipos de curvas. THEOLOGIS et al. (1993), também correlacionou a técnica ISIS com o ângulo de Cobb na escoliose idiopática do adolescente, e obteve extremos de r=0,49 a r=0,63. 
CLOSKEY \& SCHULTZ (1993) usaram um modelo biomecânico computadorizado da coluna tóraco-lombar e da caixa torácica onde simularam várias formas de escoliose e correlacionaram com medidas do ângulo de Cobb e da rotação vertebral. A correlação da protuberância lateral da caixa torácica com a rotação vertebral foi moderada $(\mathrm{r}=0,56)$ e também da rotação axial da caixa torácica com o ângulo de Cobb $(r=0,56)$.

As TABELAS 8, 9, 10 e 11 mostram os valores de correlação obtidos nesta pesquisa, que concordam com a maioria dos valores citados anteriormente pelos autores, onde a correlação das medidas de gibosidade em graus ou em centímetros para as curvas torácicas é melhor do que para curvas lombares (DUVAL-BEAUPÈRE \& LAMIREAU, 1985; STOKES, ARMSTRONG, MORELAND, 1988; PEARSALL, REID, HEDDEN, 1992), sendo que nessa pesquisa a correlação foi melhor nas posições 1 e 2 , principalmente nas radiografias na posição ortostática. Quanto as curvas tóraco-lombares a correlação é baixa e na literatura a classificação das curvas é somente em torácica e lombar ou curvas superiores e inferiores, portanto, não há parâmetros para comparação com esse resultado.

SCUTT, DANGERFIELD, DORGAN (1996), ao contrário da presente pesquisa não encontraram significante relação entre o ângulo de Cobb e a gibosidade mensurada pelo escoliômetro em qualquer posição nas curvas torácicas simples.

A fraca correlação encontrada, na presente pesquisa, das medidas de gibosidade com o ângulo de Cobb e com a rotação vertebral na região lombar e tóraco-lombar pode ser devido ao fato do não conhecimento entre os examinadores do local que a gibosidade foi medida. Nas escolioses tóraco-lombares alguns examinadores classificavam a gibosidade como torácica e outros em lombares pois a medida era feita na transição das vértebras torácicas e lombares e no momento de fazer a média destas medidas para correlacionar com as medidas radiológicas este fator poderia ter influenciado, gerando uma correlação insatisfatória ou até negativa.

Outro dado importante a ser considerado é o fato da escoliose ser uma deformidade tridimensional, ou seja, apresenta deformidades nos três planos sendo o desvio lateral no plano frontal, a rotação vertebral no plano axial e a lordose no plano 
sagital (SMITH \& DICKSON, 1987; DICKSON \& LEATHERMAN, 1988; CRUICKSHANK, KOIKE, DICKSON, 1989; DEACON, FLOOD, DICKSON, 1984; DICKSON \& LEATHERMAN, 1990); a medida de gibosidade na região tóraco-lombar pode ser influenciada e dificultada pela inversão de curvas no plano sagital que ocorre nesta região, pois a coluna torácica apresenta uma cifose com forte componente de deformidade para uma retificação ou até uma inversão da cifose e a coluna lombar com a presença de uma lordose com chances de incremento.

$\mathrm{Na}$ pesquisa de BUNNELL \& DELAWARE (1984), os autores sugeriam três diferentes angulações de inclinação anterior para o teste de Adams ao mensurar a gibosidade. Se o paciente inclina $45^{\circ}$, o examinador visualizava o tronco ao nível da coluna torácica, quando inclinava um pouco mais para diante, o examinador observava a coluna tóraco-lombar e quando o paciente estava inclinado em ângulo reto era a coluna lombar que seria melhor visualizada. Estes parâmetros de angulações deveriam ser considerados quando se utiliza medidas de gibosidade não invasivas, principalmente na região lombar e tóraco-lombar.

BROOKS et al. (1975), declaram que o teste de inclinação anterior tem se mostrado insensível na forma mais comum de escoliose que ocorre na coluna tóraco-lombar. E na pesquisa de DUVAL-BEAUPÈRE (1992), as gibosidades tóraco-lombares geralmente não eram progressivas, ou seja, a medida que a deformidade aumentava a gibosidade, como era de se esperar, não aumentava na mesma proporção o que poderia mostrar um caráter não linear deste tipo de escoliose.

A correlação das medidas de gibosidade com as medidas radiológicas em decúbito foi discretamente melhor em algumas curvas lombares e tóracolombares (TABELAS 8, 9, 10 e 11), inclusive com uma única correlação excelente das curvas lombares em decúbito (TABELA 9). A posição 3 foi usada para evitar algumas influências já citadas anteriormente, e a correlação com a radiografia em decúbito deveria ser melhor, pois também evitaria essas influências que normalmente ocorrem na radiografia em ortostático, porém os resultados mostraram uma correlação insatisfatória da posição $3 \mathrm{com}$ as medidas radiográficas em decúbito, com uma única exceção na coluna lombar, que mostrou uma correlação moderada (TABELA 9). 
A presença de coeficiente de correlação negativo nas posições 2 e 3 de curvas lombares (TABELAS 8 e 10), pode ser explicado pelas três fontes de inconsistência de mensuração citadas por WRIGHT \& FEINSTEIN (1992), ou seja, a variabilidade dos pacientes que apresentavam curvas lombares, a variabilidade do procedimento, pois a posição 3 foi a que apresentou os índices mais baixos de correlação, e a variabilidade entre os examinadores tendo em vista que a gibosidade lombar é menos visível, portanto mais difícil de ser mensurada.

Os valores da correlação da TABELA 11, mostram que o método de Raimondi correlaciona melhor com o ângulo de Cobb do que o método Nash \& Moe, com exceção apenas das curvas lombares tanto em ortostático como em decúbito. AMENDT et al. (1990), também correlacionaram o ângulo de Cobb em ortostático com a rotação vertebral pelo método Nash \& Moe com extremos de r=0,48 a 0,70 e estes valores se aproximam dos observados nesta pesquisa com extremos de $r=0,18$ a 0,65 na posição ortostática e r=0,33 a 0,41 na posição de decúbito. BURWELL et al. (1983), observaram uma correlação melhor $(r=0,89)$ do ângulo de Cobb com a rotação vertebral, pelo torsiômetro, em radiografia na posição ortostática, porém este valor era geral e não dividia por regiões da coluna como foi realizado no presente estudo.

$\mathrm{Na}$ correlação do ângulo de Cobb com a rotação vertebral, novamente um índice negativo está presente (TABELA 11), que pode ser justificado por um comportamento diferente das curvas lombares, pois estas sofrem a influência mais de perto do posicionamento da bacia e dos membros inferiores durante as medidas de gibosidade e as tomadas radiográficas na posição ortostática (STOKES \& MORELAND, 1987). Outro fato a ser considerado é que nesta região o volume dos tecidos moles que determina a gibosidade pode ser influenciado por espasmos devido a dor, encurtamento muscular ou mesmo por uma maior quantidade de tecido adiposo (DUVAL-BEAUPÈRE, 1992).

A TABELA 12 mostra que há diferença significativa das medidas do ângulo de Cobb na posição ortostática e em decúbito dorsal, sendo que na posição de decúbito é sempre menor, porém alguns autores já haviam relatado esta diferença, inclusive como sendo maior nas curvas torácicas do que nas lombares (DUVALBEAUPÈRE \& LAMIREAU, 1985; DUVAL-BEAUPÈRE, 1996). Eles observaram 
que o ângulo de Cobb em decúbito dorsal tem uma melhor correlação com a gibosidade quando a escoliose era progressiva, pois ele refletia a deformidade estrutural real sem a instabilidade e o imprevisível efeito da gravidade, enquanto que o ângulo de Cobb em ortostático expressava a condição funcional da coluna. Mas é importante ressaltar que a maioria das pesquisas utilizaram a radiografia na posição ortostática, pois caracteriza um procedimento padrão e de rotina (THULBOURNE \& GILLESPIE, 1976; BURWELL et al., 1983; NISSINEN et al., 1989; AMENDT et al., 1990; PEARSALL, REID, HEDDEN, 1992; NISSINEN et al., 1993; THEOLOGIS et al., 1993; KOROVESSIS \& STAMATAKIS, 1996; MIOR et al., 1996; SCUTT, DANGERFIELD, DORGAN, 1996; HUANG, 1997; SOUCACOS et al., 1997; CÔTÉ et al., 1998).

Nas medidas de rotação vertebral pelo método de Raimondi e pelo método Nash \& Moe não houve diferença significativa da posição ortostática com a de decúbito para as curvas lombares (TABELA 13), mostrando que neste tipo de escoliose, mais uma vez, o comportamento era diferente das demais curvas, pois a posição de decúbito não alterou significantemente os valores da rotação vertebral.

Ainda com relação a rotação vertebral, o que se observou nesta pesquisa foi que alguns pacientes apresentavam uma rotação vertebral não padrão (STOKES, 1989; STOKES \& MORELAND, 1989), onde o corpo rodava para o lado da concavidade da curva ou no caso de duas curvas a rotação era para o mesmo lado e nem sempre acompanhava a curva de maior magnitude (Anexo C, TABELA 14, pacientes $10,13,16,19,20,28,34,36,41$ e 43). Outra constatação foi quando a rotação vertebral era igual ou maior do que a magnitude da curva escoliótica (Anexo C, TABELA 14, pacientes 7, 12, 15, 19, 20, 36, 42, 43 e 44).

O método não invasivo utilizado nesta pesquisa para mensurar gibosidade clínica, pode ser recomendado com segurança, para detectar escolioses torácicas, principalmente na posição 1; mas em escolioses lombares ou tóracolombares o método não se mostrou confiável, mas por outro lado fornece um registro quantitativo que pode ser usado para acompanhamento de tratamento conservador nas escolioses leves e moderadas, porém não como um único parâmetro de mensuração, mas deve ser intercalado, obrigatoriamente, com medidas radiológicas. 
Em relação as escolioses lombares e tóraco-lombares é importante que mais pesquisas sejam realizadas com medidas não invasivas e que estas se preocupem com o máximo de esclarecimentos dos pontos de referências utilizados, do posicionamento do paciente e do equipamento, para reduzir ao mínimo possível a variabilidade entre as medidas.

As técnicas de mensuração de gibosidade podem ser usadas na prática clínica como uma método de rotina, mesmo quando realizada por vários examinadores, desde que a posição seja padronizada, pois quando se tem conhecimento do nível da coluna que foi avaliado, provavelmente, a variação será bem menor e a correlação com medidas radiológicas será bem melhor para todos os tipos de curvas na escoliose idiopática.

A escoliose é uma deformidade tridimensional, e o melhor conhecimento das variáveis clínicas e radiológicas consideradas na avaliação dessa deformidade auxiliarão no diagnóstico e tratamento dessa patologia. 


\section{CONCLUSÕES}

- Foi observado uma alta concordância das medidas de gibosidade entre os três examinadores, pois não existiram diferenças significativas entre eles;

- Quanto as três posições para medir gibosidade, a posição 1 apresentou uma melhor concordância, pois quando comparada com a posição 2 e 3 não mostrou diferença significativa, enquanto que a comparação da posição 2 com a 3 mostrou diferença significativa;

- A correlação da gibosidade com o ângulo de Cobb e com a rotação vertebral mostrou melhores resultados nas curvas torácicas, principalmente nas posições 1 e 2 e nas radiografias na posição ortostática;

- A correlação do ângulo de Cobb com a rotação vertebral pelo método de Raimondi foi melhor do que pelo método Nash \& Moe nas curvas torácicas e tóraco- lombares;

- Foram observadas diferenças significativas da magnitude da curva mensurada pelo ângulo de Cobb nas radiografias na posição ortostática e na posição de decúbito dorsal, mas as medidas de rotação vertebral pelos dois métodos mostraram diferenças significativas apenas nas curvas torácicas e tóraco-lombares. 
ANEXOS:

ANEXO A 


\section{CONSENTIMENTO PARA PARTICIPAÇÃO EM ESTUDO CLÍNICO}

Tendo sido satisfatoriamente informado sobre a pesquisa intitulada: "Estudo clínico da mensuração da gibosidade e suas correlações com medidas radiológicas na escoliose idiopática", realizada sob a responsabilidade da Profa. Dalva Minonroze Albuquerque Ferreira, concordo em ser submetido (a) a ela.

Estou também ciente de que a Profa. Dalva Minonroze Albuquerque Ferreira, estará disponível para responder a quaisquer tempo, podendo, caso não me sinta atendido(a), entrar em contato com o Chefe do Departamento de Fisioterapia ou mesmo com o Diretor da Faculdade de Ciências e tecnologia, UNESP - Campus de Presidente Prudente.

Presidente Prudente, de de 199

Assinatura do paciente ou responsável 
ANEXO B 
FICHA DE AVALIAÇÃO PARA ESCOLIOSE

\section{A - DADOS PESSOAIS}

Nome:

Registro:

Idade:

Peso: Altura:

Endereço:

Profissão anterior e atual:

Diagnóstico:

RG(Registro Geral):

Encaminhado por:

\section{B - EXAME CLÍNICO}

1) Menarca:

2) Mensuração dos MMII:D___E

3) Mensuração da gibosidade:

Torácica

Posição 1:

Posição 2:

Posição 3: D

$\mathrm{D} \_\mathrm{E}-\mathrm{E}$
$\mathrm{D} \_$E__

\section{Lombar}

$\mathrm{D}$

$\mathrm{D} \quad \mathrm{E}$

D E

Posição 1: Paciente na posição ortostática com os pés paralelos e afastados aproximadamente $10 \mathrm{~cm}$ e colocados sobre um desenho da impressão plantar com o objetivo de aumentar a base de sustentação e melhorar o equilíbrio. Solicitava-se a flexão do tronco até aproximadamente $90^{\circ}$ com os membros superiores ao longo do corpo livremente (pendurados). A seguir era realizada a mensuração da gibosidade da coluna torácica ou lombar com um nível d'água adaptado e registrado somente a maior medida da coluna torácica ou da lombar.

Posição 2: Paciente na posição ortostática como na posição 1, com flexão do tronco de aproximadamente $90^{\circ}$ e juntando as palmas das mãos (palma contra palma e dedos contra dedos, simetricamente). A seguir a gibosidade era medida como na posição 1.

Posição 3: Paciente sentado em um banco quadrado de aproximadamente $50 \mathrm{~cm}$ de altura, com o tronco flexionado para não permitir a elevação do quadril do banco, deixando os membros superiores ao lado do corpo e nivelados com o chão e lateralmente aos seus pés. A seguir a gibosidade era medida como na posição 1. 


\section{C - EXAME RADIOLÓGICO}

1) Padrão da curva:

Simples: Torácica

Tóraco-lombar

Lombar

Dupla: Torácica e lombar

Torácica

Localização:

Extensão:

Vértebra(s) apical(is):

Lado: D E

2) Medida do ângulo de Cobb:

Ortostática

Decúbito

3) Medida da rotação vertebral pelos métodos:

Raimondi:

Ortostática Decúbito
Nash \& Moe:

Ortostática
Decúbito

Observações: 
ANEXO C 


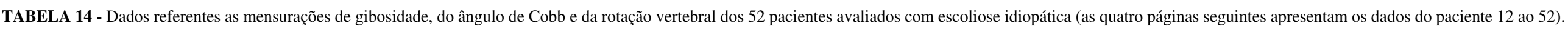

\begin{tabular}{|c|c|c|c|c|c|c|c|c|c|c|c|c|c|c|c|c|c|c|c|c|c|}
\hline \multirow{3}{*}{ Pacientes } & \multirow{3}{*}{ Posições } & \multicolumn{6}{|c|}{ Mensuração de Gibosidade (cm) * } & \multicolumn{6}{|c|}{ Medida do ângulo de Cobb (graus) $\dagger$} & \multicolumn{8}{|c|}{ Medida de Rotação vertebral $\ddagger$} \\
\hline & & \multicolumn{2}{|c|}{ 1. examinador } & \multicolumn{2}{|c|}{ 2. examinador } & \multicolumn{2}{|c|}{ 3. examinador } & \multicolumn{3}{|c|}{ Ortostático } & \multicolumn{3}{|c|}{ Decúbito } & \multicolumn{4}{|c|}{ Raimondi (graus) } & \multicolumn{4}{|c|}{ Nash \& Moe (graduação + } \\
\hline & & $\mathbf{T}$ & $\mathbf{L}$ & $\mathbf{T}$ & $\mathbf{L}$ & $\mathbf{T}$ & $\mathbf{L}$ & $\mathbf{T}$ & $\mathbf{L}$ & TL & $\mathbf{T}$ & $\mathbf{L}$ & TL & Ortost & tático & Dect & íbito & Ortos & ático & Dec & íbito \\
\hline 1 & $\begin{array}{l}1 \\
2 \\
3\end{array}$ & $\begin{array}{l}0.50 \\
0.55 \\
0.40\end{array}$ & & $\begin{array}{l}0.30 \\
0.30 \\
0.20\end{array}$ & & & $\begin{array}{l}1.00 \\
0.90 \\
1.00\end{array}$ & & & 9 & & & 6 & 8 & & 6 & & + & & + & \\
\hline 2 & $\begin{array}{l}1 \\
2 \\
3\end{array}$ & & $\begin{array}{l}-0.80 \\
-0.60 \\
-0.60\end{array}$ & $\begin{array}{l}-0.40 \\
-0.40 \\
-0.30\end{array}$ & & & $\begin{array}{l}-0.40 \\
-0.30 \\
-0.30\end{array}$ & -7 & & & -4.5 & & & -3 & & -3 & & + & & + & \\
\hline 3 & $\begin{array}{l}1 \\
2 \\
3\end{array}$ & $\begin{array}{l}-0.30 \\
-0.30 \\
-0.20\end{array}$ & & 0.20 & $\begin{array}{l}-0.60 \\
-0.40\end{array}$ & $\begin{array}{l}0.30 \\
---- \\
0.50\end{array}$ & & & & -8 & & & -2 & -7 & & -7 & & + & & + & \\
\hline 4 & $\begin{array}{l}1 \\
2 \\
3\end{array}$ & $\begin{array}{l}0.30 \\
0.30 \\
0.40\end{array}$ & & $\begin{array}{l}0.40 \\
0.40 \\
0.30\end{array}$ & & $\begin{array}{l}0.20 \\
0.50 \\
0.30\end{array}$ & & 5 & & -6 & 2 & & -4 & 2 & -1.5 & 1 & 0 & + & 0 & 0 & 0 \\
\hline 5 & $\begin{array}{l}1 \\
2 \\
3\end{array}$ & $\begin{array}{l}-0.20 \\
-0.30 \\
-0.40\end{array}$ & & $\begin{array}{l}-0.25 \\
-0.10 \\
-0.35\end{array}$ & & $\begin{array}{l}-0.20 \\
-0.10 \\
-0.10\end{array}$ & & & & -18 & & & -15 & -12 & & -10 & & + & & + & \\
\hline 6 & $\begin{array}{l}1 \\
2 \\
3\end{array}$ & $\begin{array}{l}2.30 \\
1.90 \\
1.30\end{array}$ & & $\begin{array}{l}1.60 \\
1.40 \\
0.70\end{array}$ & & $\begin{array}{l}1.60 \\
1.60 \\
0.70\end{array}$ & & $40 /-20$ & -22 & & ---- & & ---- & $18 /-10$ & -4 & ---- & --- & $++/+$ & + & ---- & ---- \\
\hline 7 & $\begin{array}{l}1 \\
2 \\
3\end{array}$ & $\begin{array}{l}1.30 \\
1.60 \\
1.25\end{array}$ & & $\begin{array}{l}0.80 \\
0.90 \\
0.40\end{array}$ & & $\begin{array}{l}1.30 \\
0.80 \\
1.00\end{array}$ & & & & 10 & & & 8.5 & 15 & & 7 & & ++ & & + & \\
\hline 8 & $\begin{array}{l}1 \\
2 \\
3\end{array}$ & $\begin{array}{l}-2.00 \\
-1.80 \\
-1.80\end{array}$ & & $\begin{array}{l}-2.30 \\
-2.30 \\
-2.30\end{array}$ & & $\begin{array}{l}-1.70 \\
-1.85 \\
-1.70\end{array}$ & & -28 & & & ---- & & & -16 & & ---- & & +++ & & ---- & \\
\hline 9 & $\begin{array}{l}1 \\
2 \\
3\end{array}$ & $\begin{array}{l}1.10 \\
0.40 \\
1.40\end{array}$ & & $\begin{array}{l}0.30 \\
0.30 \\
0.80\end{array}$ & & $\begin{array}{l}0.40 \\
0.40 \\
0.70\end{array}$ & & & & 8 & & & 6 & 6 & & 3 & & + & & + & \\
\hline $10^{A 1}$ & $\begin{array}{l}1 \\
2 \\
3\end{array}$ & $\begin{array}{l}0.40 \\
0.45 \\
0.60\end{array}$ & & & $\begin{array}{r}-0.40 \\
-0.30 \\
0.90\end{array}$ & -0.50 & $\begin{array}{l}0.30 \\
0.30\end{array}$ & -12.5 & & 11 & -9 & & -10 & 0 & 4 & 2 & 2 & 0 & + & 0 & 0 \\
\hline 11 & $\begin{array}{l}1 \\
2 \\
3\end{array}$ & $\begin{array}{l}0.80 \\
0.80 \\
0.65\end{array}$ & & $\begin{array}{l}1.00 \\
1.10 \\
0.70\end{array}$ & & $\begin{array}{l}0.80 \\
0.50 \\
0.40\end{array}$ & & 18 & & -10 & 13.5 & & -8.5 & 4 & -6 & 2 & -2 & + & + & 0 & 0 \\
\hline
\end{tabular}




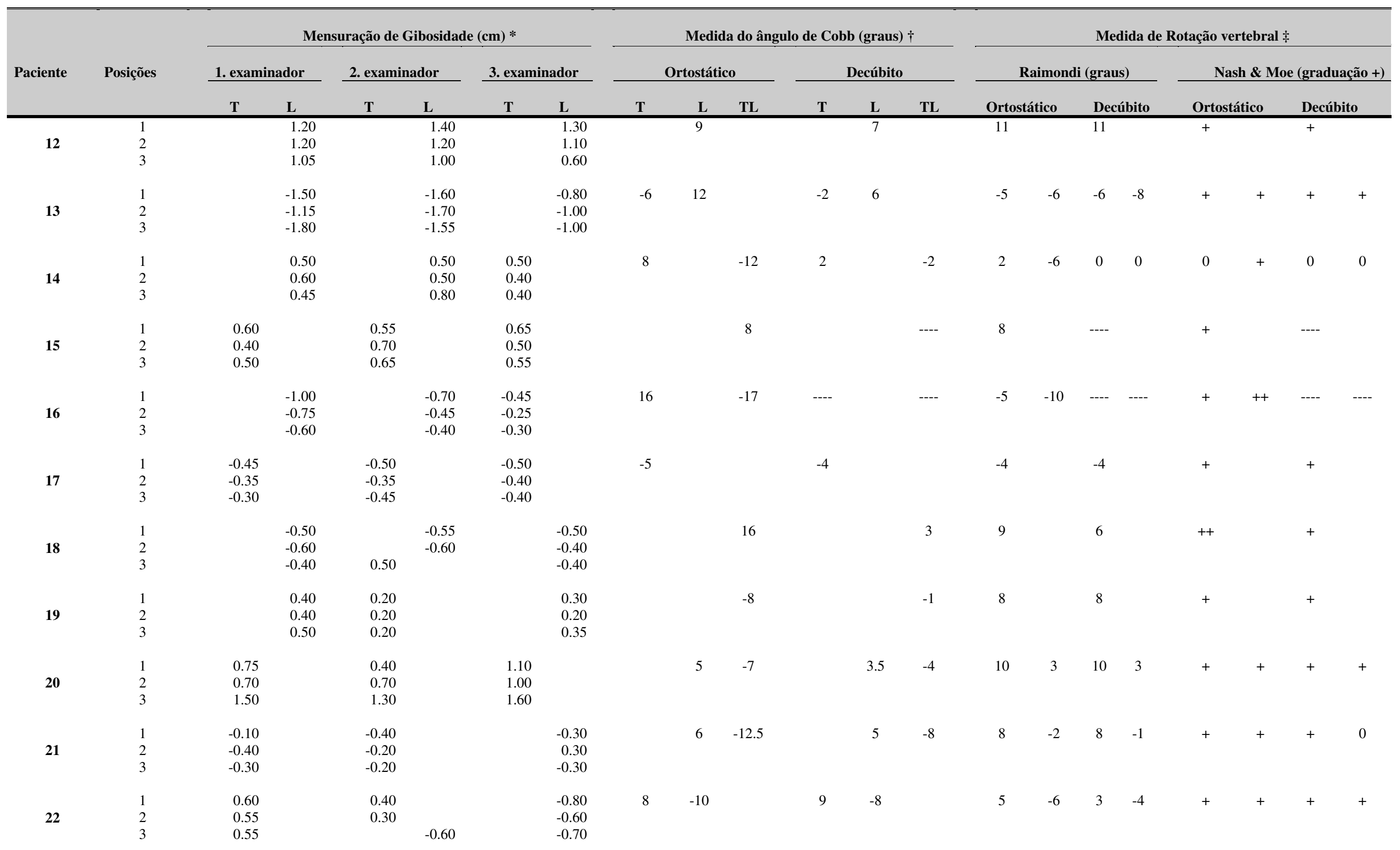




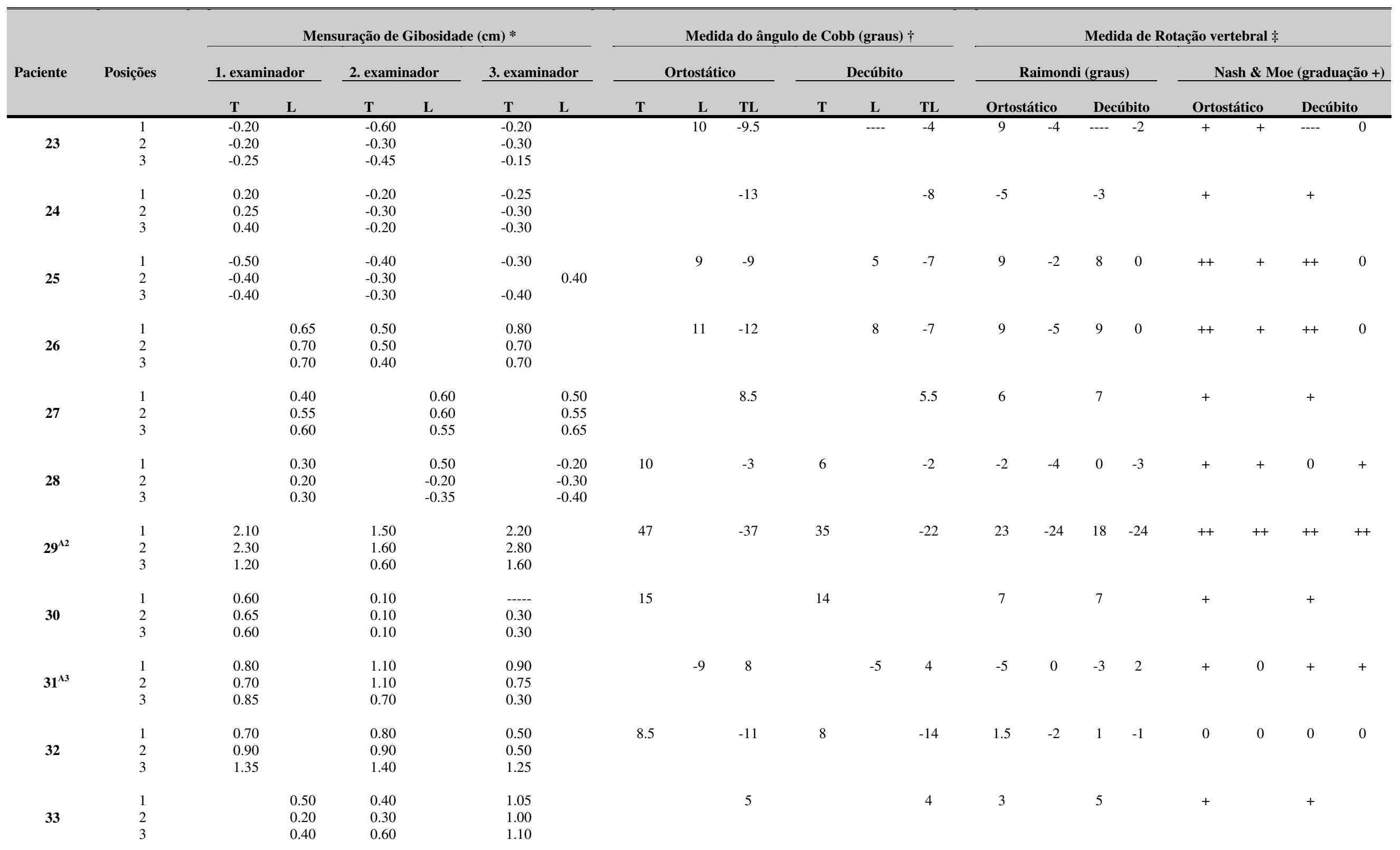




\begin{tabular}{|c|c|c|c|c|c|c|c|c|c|c|c|c|c|c|c|c|c|c|c|c|c|}
\hline \multirow{3}{*}{ Paciente } & \multirow{3}{*}{ Posições } & \multicolumn{6}{|c|}{ Mensuração de Gibosidade (cm) * } & \multicolumn{6}{|c|}{ Medida do ângulo de Cobb (graus) $\dagger$} & \multicolumn{8}{|c|}{ Medida de Rotação vertebral $\ddagger$} \\
\hline & & \multicolumn{2}{|c|}{ 1. examinador } & \multicolumn{2}{|c|}{ 2. examinador } & \multicolumn{2}{|c|}{ 3. examinador } & \multicolumn{3}{|c|}{ Ortostático } & \multicolumn{3}{|c|}{ Decúbito } & \multicolumn{4}{|c|}{ Raimondi (graus) } & \multicolumn{4}{|c|}{ Nash \& Moe (graduação +) } \\
\hline & & $\mathbf{T}$ & $\mathbf{L}$ & $\mathbf{T}$ & $\mathbf{L}$ & $\mathbf{T}$ & $\mathbf{L}$ & $\mathbf{T}$ & $\mathbf{L}$ & TL & $\mathbf{T}$ & $\mathbf{L}$ & TL & Ortost: & tico & Dec & úbito & Ortost: & & Decú & \\
\hline 34 & $\begin{array}{l}1 \\
2 \\
3\end{array}$ & & $\begin{array}{l}0.50 \\
0.35 \\
0.30\end{array}$ & & $\begin{array}{l}0.30 \\
0.30 \\
0.20\end{array}$ & & $\begin{array}{l}0.40 \\
0.25 \\
0.30\end{array}$ & & & -6.5 & & & -2 & 5 & & 2 & & + & & 0 & \\
\hline 35 & $\begin{array}{l}1 \\
2 \\
3\end{array}$ & $\begin{array}{r}0.40 \\
-0.40 \\
-0.30\end{array}$ & & $\begin{array}{l}0.40 \\
0.40 \\
0.30\end{array}$ & & $\begin{array}{l}0.30 \\
0.40 \\
0.20\end{array}$ & & 6 & -15 & & 4 & -8.5 & & 5 & -6 & 5 & -6 & & + & + & + \\
\hline 36 & $\begin{array}{l}1 \\
2 \\
3\end{array}$ & & $\begin{array}{l}-0.35 \\
-0.30 \\
-0.30\end{array}$ & $\begin{array}{l}-0.20 \\
-0.20 \\
-0.20\end{array}$ & & & $\begin{array}{l}-0.35 \\
-0.25 \\
-0.20\end{array}$ & -10 & & 9 & -4 & & 1 & 11 & 15 & 4 & 9 & ++ & ++ & + & ++ \\
\hline 37 & $\begin{array}{l}1 \\
2 \\
3\end{array}$ & $\begin{array}{l}0.25 \\
0.40 \\
0.50\end{array}$ & & & $\begin{array}{l}-0.20 \\
-0.20 \\
-0.10\end{array}$ & $\begin{array}{l}0.60 \\
0.40 \\
0.40\end{array}$ & & 8 & & & 7 & & & 4 & & 6 & & + & & + & \\
\hline 38 & $\begin{array}{l}1 \\
2 \\
3\end{array}$ & & $\begin{array}{l}0.20 \\
0.20 \\
0.30\end{array}$ & $\begin{array}{l}0.60 \\
0.60 \\
0.70\end{array}$ & & & $\begin{array}{l}0.25 \\
0.35 \\
0.20\end{array}$ & ---- & ---- & ---- & --- & --- & ---- & ---- & ---- & ---- & ---- & ---- & ---- & ---- & ---- \\
\hline 39 & $\begin{array}{l}1 \\
2 \\
3\end{array}$ & 0.35 & $\begin{array}{l}-0.25 \\
-0.40\end{array}$ & $\begin{array}{l}-0.30 \\
-0.30 \\
-0.20\end{array}$ & & & $\begin{array}{l}0.30 \\
0.20 \\
1.00\end{array}$ & $11 /-5$ & & 5 & $10 /-7$ & & 3 & $8 /-4$ & ---- & $8 /-4$ & --- & + & + & + & + \\
\hline 40 & $\begin{array}{l}1 \\
2 \\
3\end{array}$ & $\begin{array}{l}-0.30 \\
-0.40 \\
-0.30\end{array}$ & & $\begin{array}{l}-0.20 \\
-0.20 \\
-0.15\end{array}$ & & $\begin{array}{l}-0.20 \\
-0.20 \\
-0.35\end{array}$ & & -13 & & 6 & -13 & & 3.5 & -2 & 8 & 0 & 8 & 0 & + & 0 & + \\
\hline 41 & $\begin{array}{l}1 \\
2 \\
3\end{array}$ & $\begin{array}{l}0.75 \\
0.75 \\
1.40\end{array}$ & & $\begin{array}{l}0.50 \\
0.50 \\
0.45\end{array}$ & & $\begin{array}{l}0.60 \\
0.70 \\
0.65\end{array}$ & & 14 & & -15 & 13 & & -8 & 6 & 3 & 2 & -6 & + & + & 0 & + \\
\hline 42 & $\begin{array}{l}1 \\
2 \\
3\end{array}$ & $\begin{array}{l}-0.40 \\
-0.40 \\
-0.20\end{array}$ & & $\begin{array}{l}-0.35 \\
-0.20 \\
-0.35\end{array}$ & & & $\begin{array}{l}-0.50 \\
-0.45 \\
-0.30\end{array}$ & -6 & & 3 & -4 & & 6.5 & -9 & 4 & -2 & 9 & + & + & 0 & + \\
\hline $\mathbf{4 3}^{\mathrm{A4}}$ & $\begin{array}{l}1 \\
2 \\
3\end{array}$ & & $\begin{array}{l}-0.50 \\
-0.30 \\
-0.20\end{array}$ & & $\begin{array}{l}-0.40 \\
-0.45 \\
-0.25\end{array}$ & & $\begin{array}{l}-0.40 \\
-0.30 \\
-0.20\end{array}$ & & & 10 & & & 5 & 5 & -8 & 2 & -4 & + & + & 0 & + \\
\hline 44 & $\begin{array}{l}1 \\
2 \\
3\end{array}$ & & $\begin{array}{l}-0.40 \\
-0.65 \\
-0.50\end{array}$ & & $\begin{array}{l}-0.70 \\
-0.55 \\
-0.65\end{array}$ & & $\begin{array}{l}-0.70 \\
-0.90 \\
-0.70\end{array}$ & & & -20 & & & -12 & -22 & & -20 & & +++ & & ++ & \\
\hline
\end{tabular}




\begin{tabular}{|c|c|c|c|c|c|c|c|c|c|c|c|c|c|c|c|c|c|c|c|c|c|}
\hline \multirow{3}{*}{ Paciente } & \multirow{3}{*}{ Posições } & \multicolumn{6}{|c|}{ Mensuração de Gibosidade (cm) * } & \multicolumn{6}{|c|}{ Medida do ângulo de Cobb (graus) $\dagger$} & \multicolumn{8}{|c|}{ Medida de Rotação vertebral $\ddagger$} \\
\hline & & \multicolumn{2}{|c|}{ 1. examinador } & \multicolumn{2}{|c|}{ 2. examinador } & \multicolumn{2}{|c|}{ 3. examinador } & \multicolumn{3}{|c|}{ Ortostático } & \multicolumn{3}{|c|}{ Decúbito } & \multicolumn{4}{|c|}{ Raimondi (graus) } & \multicolumn{4}{|c|}{ Nash \& Moe (graduação +) } \\
\hline & & $\mathbf{T}$ & $\mathbf{L}$ & $\mathbf{T}$ & $\mathbf{L}$ & $\mathbf{T}$ & $\mathbf{L}$ & $\mathbf{T}$ & $\mathbf{L}$ & TL & $\mathbf{T}$ & $\mathbf{L}$ & TL & Ortos & tico & Dec & úbito & Orto & tico & Dec & \\
\hline 45 & $\begin{array}{l}1 \\
2 \\
3\end{array}$ & & $\begin{array}{l}-1.05 \\
-1.10 \\
-1.00\end{array}$ & & $\begin{array}{l}-0.80 \\
-0.70 \\
-0.70\end{array}$ & & $\begin{array}{l}-0.70 \\
-0.80 \\
-1.00\end{array}$ & 13 & & -15 & 11 & & -14 & 7 & -13 & 3 & -13 & + & ++ & + & ++ \\
\hline 46 & $\begin{array}{l}1 \\
2 \\
3\end{array}$ & & $\begin{array}{l}0.45 \\
0.45 \\
0.50\end{array}$ & $\begin{array}{l}-0.70 \\
-0.60 \\
-0.90\end{array}$ & & & $\begin{array}{l}0.40 \\
0.30 \\
0.50\end{array}$ & 18 & & -36.5 & 12 & & -25 & 6 & -14 & 2 & -12 & + & ++ & 0 & ++ \\
\hline $47^{\mathrm{As}}$ & $\begin{array}{l}1 \\
2 \\
3\end{array}$ & $\begin{array}{l}0.50 \\
0.65 \\
0.20\end{array}$ & & & $\begin{array}{l}0.65 \\
0.75 \\
0.40\end{array}$ & & $\begin{array}{l}0.75 \\
0.75 \\
0.60\end{array}$ & -6 & & 14 & --- & & --- & -3 & 7 & ---- & ---- & 0 & + & ---- & ---- \\
\hline 48 & $\begin{array}{l}1 \\
2 \\
3\end{array}$ & $\begin{array}{l}-0.50 \\
-0.40 \\
-0.50\end{array}$ & & $\begin{array}{l}-0.45 \\
-0.25 \\
-0.25\end{array}$ & & $\begin{array}{l}-0.30 \\
-0.35 \\
-0.20\end{array}$ & & --- & ---- & --- & ---- & --- & ---- & ---- & --- & ---- & --- & --- & ---- & ---- & ---- \\
\hline 49 & $\begin{array}{l}1 \\
2 \\
3\end{array}$ & $\begin{array}{l}0.40 \\
0.50 \\
0.35\end{array}$ & & $\begin{array}{l}0.30 \\
0.20 \\
0.25\end{array}$ & & & $\begin{array}{l}-0.40 \\
-0.50 \\
-0.50\end{array}$ & --- & ---- & --- & ---- & --- & --- & --- & ---- & ---- & ---- & ---- & --- & ---- & ---- \\
\hline 50 & $\begin{array}{l}1 \\
2 \\
3\end{array}$ & & $\begin{array}{l}-0.70 \\
-0.35 \\
-0.40\end{array}$ & & $\begin{array}{l}-0.50 \\
-0.30 \\
-0.20\end{array}$ & & $\begin{array}{r}-0.50 \\
-0.80 \\
-0.70\end{array}$ & ---- & ---- & --- & ---- & ---- & ---- & --- & ---- & ---- & ---- & ---- & ---- & ---- & ---- \\
\hline $51^{\mathrm{A6}}$ & $\begin{array}{l}1 \\
2 \\
3\end{array}$ & & $\begin{array}{l}-0.60 \\
-0.60 \\
-0.65\end{array}$ & & $\begin{array}{l}-0.40 \\
-0.40 \\
-0.70\end{array}$ & & $\begin{array}{l}-0.50 \\
-0.55 \\
-0.60\end{array}$ & & -5 & & & -3 & & -2 & & -2 & & 0 & & 0 & \\
\hline 52 & $\begin{array}{l}1 \\
2 \\
3\end{array}$ & & $\begin{array}{l}-0.30 \\
-0.40 \\
-0.45\end{array}$ & & $\begin{array}{l}-0.30 \\
-0.20 \\
-0.30\end{array}$ & $\begin{array}{l}-0.60 \\
-0.45 \\
-0.50\end{array}$ & & -2.5 & & 12 & -5 & & 4 & -2 & 8 & -2 & 6 & 0 & + & 0 & + \\
\hline
\end{tabular}

* $\mathrm{O}$ valor positivo indica gibosidade para o lado direito e o valor negativo indica gibosidade para o lado esquerdo. $\mathrm{T}=$ gibosidade torácica, $\mathrm{L}=$ gibosidade lombar

$\dagger \mathrm{O}$ valor positivo indica curva que é convexa para o lado direito e o valor negativo indica curva que é convexa para o lado esquerdo. $\mathrm{T}=$ curva torácica, $\mathrm{L}=\mathrm{curva}$ lombar, $\mathrm{TL}=\mathrm{curva}$ tóraco-lombar.

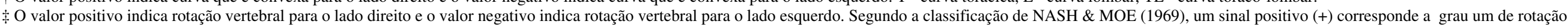
vertebral, dois sinais positivos (++) grau dois de rotação vertebral e três sinais positivos (+++) grau três de rotação vertebral.

$10^{\mathrm{A1}}=$ assimetria de $0,3 \mathrm{~cm}$ pelo escanograma;

$29^{\mathrm{A} 2}=$ assimetria de $1,2 \mathrm{~cm}$ pelo escanograma;

$31^{\mathrm{A} 3}=$ assimetria de $1,0 \mathrm{~cm}$ pelo escanograma;

$43^{\mathrm{A4}}=$ assimetria de $1,6 \mathrm{~cm}$ pelo escanograma;

$47^{\mathrm{AS}}=$ assimetria de $0,3 \mathrm{~cm}$ pelo escanograma;

$51^{\mathrm{A} 6}=$ assimetria de $1,0 \mathrm{~cm}$ pelo escanograma 


\section{REFERÊNCIAS BIBLIOGRÁFICAS ${ }^{1}$}

AMENDT, L. E. et al. (1990). Vality and realiability of the scoliometer. Physical Therapy, v.70, n.2, p.56/ 108-65/117.

APLEY, A. G. (1989). Manual de ortopedia e fraturas. Rio de Janeiro: Atheneu, p. 229-237.

ARDRAN, G. M. et al. (1980). Assessment of scoliosis in children: low dose radiographic technique. Britsh Journal of Radiology, v.53, p.146-147.

ARKIN, A. M. (1950). The mecanism of rotation in combination with lateral deviation in the normal spine. The Journal of Bone and Joint Surgery, v.32A, n.1, p. 180-188.

BASMAJIAN, J. V. (1987). Terapêutica por exercícios. 3. ed. São Paulo: Manole, p.557-579.

BEALS, R. K. (1973). Nosologic and genetic aspects of scoliosis. Clinical Orthopaedics and Related Research, n.93, p.23.

BEAUCHAMP, M. et al. (1993). Diurnal variation of Cobb angle measurement in adolescent idiopathic scoliosis. Spine, v.18, n.12, p.1581-1583.

BERQUÓ, E. (1981). Bioestatística. São Paulo: EPU, 350p.

\footnotetext{
${ }^{1}$ ABNT-SIBi/USP-1996
} 
BIRCHALL, D. et al. (1997). Measurement of vertebral rotation in adolescent idiopathic scoliosis using three-dimensional magnetic resonance imaging. Spine, v.22, n.20, p.2403-2407.

BROOKS, H. L. et al. (1975). Scoliosis: a prospective epidemiological study. The Journal of Bone and Joint Surgery, v.57-B, n.7, p.968-972.

BUNNELL, W. P. (1986). Spinal deformity. Pediatric Clinics of North America, v.33, n.6, p.1475-1487.

BUNNELL, W. P. (1993). Outcome of spinal screnning. Spine, v.18, n.12, p.15721580.

BUNNELL, W. P.; DELAWARE, W. (1984). An objective criterion for scoliosis screening. The Journal of Bone and Joint Surgery, v.64-A, n.9, p.1381-1387.

BURWELL, R. G. et al. (1982). The rib hump score: a guide to referral and prognosis? The Journal of Bone and Joint Surgery, v.64-B, p.248.

BURWELL, R. G. et al. (1983). Standardised trunk asymmetry scores: a study of back contour in healthy schoolchildren. The Journal of Bone and Joint Surgery, v.65-B, n.4, p.452-463.

BYRD III, J. A. (1988). Current theories on the etiology of idiopathic scoliosis. Clinical Orthopaedics and related Research, n.229, p.114-119.

CAILLIET, R. (1977). Escoliose - Diagnóstico e tratamento. São Paulo: Manole, p.17-54.

CARMAN, D. L.; BROWNE, R. H.; BIRCH, J. G. (1990). Measurement of scoliosis and kyphosis radiographs. The Journal of Bone and Joint Surgery, v.72-A, n.3, p.328-333. 
CARR, A. J. et al. (1989). Correction of body heigth in scoliotic patients using ISIS scanning. Spine, v.14, n.2, p.220-222.

CARR, A. J. et al. (1991). An analysis of normal back shape measured by ISIS scanning. Spine, v.16, n.6, p.656-659.

CHAPCHAL, G.; WAIGAND, D. (1973). Terapeutica ortopedica. Barcelona: Salvat, p.350-384.

CICCHETTI, H. L.; SPARROW, S. A. (1981). Developing criteria for establishing interrater reliability of specific items: applications to assement of adaptive behavior. American Journal of Mental Deficiency, v.86, p.127-137.

CLOSKEY, R. F.; SCHULTZ, A. B. (1993). Rib cage deformities in scoliosis: spine morphology, rib cage stiffness, and tomography imaging. Journal of Orthopaedic Research, v.11, n.5, p.730-737.

COILLARD, C.; RIVARD, C. H. (1996). Vertebral deformities and scoliosis. European Spine Journal, v.5, p.91-100.

COSTA NETO, P. L . O. (1977). Estatística. São Paulo: Edgard Blücher, 264p.

CÔTÉ, P. et al. (1998). A study of the diagnostic accuracy and reliability of the scoliometer and Adam's forward bend test. Spine, v.23, n.7, p.796-803.

CRUICKSHANK, J. L.; KOIKE, M.; DICKSON, R. A. (1989). Curve patterns in idiopathic scoliosis: A clinical and radiographic study. The journal of Bone and Joint Surgery, v.71-B, n.2, p.259-263. 
DEACON, P.; FLOOD, B. M.; DICKSON, R. A. (1984). Idiopathic scoliosis in three dimensions. A radiographic and morphometric analysis. The Journal of Bone and Joint Surgery, v.66-B, n.4, p.509-512.

DICKSON, R. A. (1983). Scoliosis in the community. British Medical Journal, v.286, p.615-618.

DICKSON, R. A. (1988). The aetiology of spinal deformities. The Lancet, v.21, p.1151-1154.

DICKSON, R. A.; LEATHERMAN, K. D. (1988). The management of spinal deformities. London: Wright, p.1-54.

DICKSON, R. A.; LEATHERMAN, K. D. (1990). Spinal deformities. In: DICKSON, R. A. Spinal surgery: science and practice. London: Butterworths, p.368-435.

D'OSUALDO, F.; SCHIERANO, S.; IANNIS, M. (1997). Validation of clinical measurement of kyphosis with a simple instrument, the arcometer. Spine, v.22, n.4, p.408-413.

DRERUP, B. (1981). Procedure for the numerical analysis of Moiré topograms. Photogrammetric, v.36, n.2, p.41-49.

DRERUP, B. (1984). Principles of measurement of vertebral rotation from frontal projections of the pedicles. Journal of Biomechanics, v.17, p.923-935.

DRERUP, B.; HIERHOLZER, E. (1987). Automatic localization of anatomical landmarks on the back surface and construction of a body-fixed coordinate system. Journal of Biomechanics, v.20, n.10, p.961-970. 
DRERUP, B.; HIERHOLZER, E. (1992a). Evaluation of frontal radiographs of scoliotic spines: Part I. Measurement of position and orientation of vertebrae and assessment of clinical shape parameters. Journal of Biomechanics, v.25, n.12, p.1443-1450.

DRERUP, B.; HIERHOLZER, E. (1992b). Evaluation of frontal radiographs of scoliotic spines: Part II. Relations between lateral deviation, lateral tilt and axial rotation of vertebrae. Journal of Biomechanics, v.25, n.11, p.1357-1362.

DUVAL-BEAUPÈRE, G. (1992). Rib hump and supine angle as prognostic factors for mild scoliosis. Spine, v.17, n.1, p.103-107.

DUVAL-BEAUPÈRE, G. (1996). Threshold values for supine and standing Cobb angles and rib hump measurements: prognostic factors for scoliosis. European Spine Journal, v.5, p.79-84.

DUVAL-BEAUPÈRE, G.; LAMIREAU, T. (1985). Scoliosis at less than $30^{\circ}$ : properties of the evolutivity (risk of progression). Spine, v.10, n.5, p.421-424.

ELAD, D.; EINAV, S. (1990). Three-dimensional measurement of biological surfaces. ISPRS Journal of Photogrammetry and Remote Sensing, v.45, n.4, p.247-266.

FERREIRA, A. B. H. (1988). Dicionário Aurélio básico da língua portuguesa. Rio de Janeiro: Nova Fronteira, 687p.

FISCHINGER, B. (1982). A escoliose vista por um fisioterapeuta. Rio de Janeiro: EDUCS, p.34-43.

FROBIN, W.; HIERHOLZER, E. (1981). Rasterstereography : a photogrammetric method for measurement of body surfaces. Photogrammetric Engineering and Remote Sensing, v.47, n.12, p.1717-1724. 
FROBIN, W.; HIERHOLZER, E. (1983a). Automatic measurement of body surfaces using rasterstereography: Part I. Photogrammetric Engineering and Remote Sensing, v.49, n.3, p.377-384.

FROBIN, W.; HIERHOLZER, E. (1983b). Automatic measurement of body surfaces using rasterstereography: Part II. Photogrammetric Engineering and Remote Sensing, v.49, n.10, p.1443-1452.

FROBIN, W.; HIERHOLZER, E. (1991). Video rasterstereography : a method for on-line measurement of body surfaces. Photogrammetric Enginnering and Remote Sensing, v.57, n.10, p.1341-1345.

GOLDSTEIN, L. A.; WAUGH, T. R. (1973). Classification and terminology of scoliosis. Clinical Orthopaedic and Related Research, n.93, p.10-22.

GRACOVETSKY, S. et al. (1995). A database for estimating normal spinal motion derived from noninvasive measurements. Spine, v.20, n.9, p.1036-1046.

GRAM, M. C.; HASAN, Z. (1999). The spinal curve in standing and sitting postures in children with idiopathic scoliosis. Spine, v.24, n.2, p.169-177.

GRANATA, C. et al. (1989). Spinal muscular atrophy : natural history and orthopaedic treatment of scoliosis. Spine, v.14, n.7, p.760-762.

GUNZBURG, R. et al. (1991). Radiologic interpretation of lumbar vertebral rotation. Spine, v.16, n.6, p.660-664.

HALLERT, B. (1960). Photogrammetry: Basic principles and general survey. London : Mc Graw-Hill Book Company, p.23. 
HO, E. K. W. et al. (1992). A comparative study of computed tomographic and plain radiographic methods to measure vertebral rotation in adolescent idiopathic scoliosis. Spine, v.17, n.7, p.771-774.

HOIKKA, V.; YLIOSKI, M.; TALLROTH, K. (1989). Leg-length inequality has poor correlation with lumbar scoliosis. Archives of Orthopaedic and Trauma Surgery, v.108, p.173-175.

HOPPENFELD, S. (1980). Propedêutica Ortopédica: coluna e extremidades. Rio de Janeiro: Atheneu, p.172-174.

HUANG,S-C. (1997). Cutt-off point of the scoliometer in school scoliosis screening. Spine, v.22, n.17, p.1985-1989.

JEFFRIES, B. F. et al. (1980). Computerized measurement and analysis of scoliosis. Pediatric Radiology, v.134, p.381-385.

KISNER, C.; COLBY, L. A. (1987). Exercícios terapêuticos. São Paulo: Manole, p. 529-537.

KOGUT,M. S.; WARREN, F. H.; KALMAR, J. A. (1989). Low dose imaging of scoliosis: use of a computed radiographic imaging system. Pediatric Radiology, v.20, p.85-86.

KOJIMA, T.; KUROKAWA, T. (1992). Rotation vector, a new method for representation of three-dimensional deformity in scoliosis. Spine, v.17, n.11, p.1296-1303.

KOROVESSIS, P.G.; STAMATAKIS, M. V. (1996). Prediction of scoliotic Cobb angle with the use of the scoliometer. Spine, v.21, n.14, p.1661-1666. 
KRISMER, M. et al. (1996). Axial rotation measurement of scoliotic vertebrae by means of computed tomography scans. Spine, v.21, n.5, p.576-581.

LANE III, H. B. (1983). Photogrammetry in medicine. Photogrammetric Engineering and Remote Sensing, v.49, n.10, p.1453-1456.

LIU, S-L.; HUANG, D-S. (1996). Scoliosis in China. Clinical Orthopaedics and Related Research, n.323, p.113-118.

LOPEZ-SOSA, F.; GUILLE, J. T.; BOWEN, J. R. (1995). Rotation of the spine in congenital scoliosis. Journal of Pediatric Orthopaedics, v.15, n.4, p.528-534.

MEHTA, M.H. (1972). The rib-vertebra angle in the early diagnosis between resolving and progressive infantile scoliosis. The Journal of Bone and Joint Surgery, v.54-B, n.2, p.230-243.

MIOR, S. A. et al. (1996). A comparison of radiographic and electrogoniometric angles in adolescent idiopathic scoliosis. Spine, v.21, n.13, p.1549-1555.

MORRISSY, R. T. et al. (1990). Measurement of the Cobb angle on radiographs of patients who have scoliosis. The Journal of Bone and Joint Surgery, v.72-A, n.3, p.320-327.

MURRELL, G. A. C. et al. (1993). An assesssment of the reliability of the scoliometer. Spine, v.18, n.6, p.709-712.

NASH, C. L. et al. (1979). Risks of exposure to x-rays in patients undergoing longterm treatment for scoliosis. The Journal of Bone and Joint Surgery, v.61-A, n.3, p.371-374.

NASH, C.L.; MOE, J. H. (1969). A study of vertebral rotation. The Journal of Bone and Joint Surgery, v.51-A, n.2, p.223-229. 
NEWTON, I. (1980). Medical Photogrammetry. In: ATKINSON, K. B. Developments in close range photogrammetry - 1. London: Applied Science Publishers, p.117-48.

NISSINEN, M. et al. (1989). Trunk asymmetry and scoliosis. Acta Paediatric Scandinavic, v.78, p.747-753.

NISSINEN, M. et al. (1993). Trunk asymmetry, posture, growth, and risk of scoliosis: a three-year follow-up of finnish prepuberal school children. Spine, v.18, n.1, p.8-13.

ÖMEROGLU,H.; ÖZEKIN, O.; BIÇIMOGLU, A. (1996). Measurement of vertebral rotation in idiophatic scoliosis using the Perdriolle torsiometer: a clinical study on intraobserver and interabserver error. European Spine Journal, v.5, p.167-171.

PEARSALL, D.J.; REID, J. G.; HEDDEN, D. M. (1992). Compararison of three noninvasive method for measuring scoliosis. Physical Therapy, v.72, n.9, p.648/35-657/44.

PERDRIOLLE, R. et al. (1993). Mechanical process and growth cartilages: essential factors in the progression of scoliosis. Spine, v.18, n.3, p.343-349.

PERDRIOLLE, R.; VIDAL, J. (1981). Étude de la courbure scoliotique: importance de l'extension et de la rotation vertébrale. Revue de Chirurgie Orthopédique, v.67, p.25-34.

PITZEN , P.; RÖSSLER, H. (1981). Manual de ortopedia. São Paulo: Atheneu, p. $200-214$. 
RICHARDS, B. S. (1992). Measurement error in assesssment of vertebral rotation using the Perdriolle torsionmeter. Spine, v.17, n.5, p.513-517.

ROSENBERGT, N. et al. (1990). Simplified remote measurement of threedimensional surfaces: application for biomedical engineering. Photogrammetric Engineering and Remote Sensing, v.56, n.9, p.1273-1280.

ROWE, D. E. et al. (1997). A meta analysis of back pain in children who have idiopathic scoliosis. The Journal of Bone and Joint Surgery, v.79-A, n.5, p.664-674.

RUSSEL, G. G. et al. (1990). A comparison of four computerized methods for measuring vertebral rotation. Spine, v.15, n.1, p.24-27.

SCHULTZ, A. B. (1991). The use of mathematical models for studies of scoliosis biomechanics. Spine, v.16, n.10, p.1211-1216.

SCUTT,N. D.; DANGERFIELD,P. H.; DORGAN, J. C. (1996). The relation between surface and radiological deformity in adoslecent idiopathic scoliosis: effect of chance in body position. European Spine Journal, v.5, p.85-90.

SEVASTIKOGLOU, J. A.; BERGQUIST, E. (1969). Evaluation of the reliability of radiological methods for registration of scoliosis. Acta Orthopaedic Scandinavian, v.40, p.608-613.

SHEA, K. G. et al. (1998). A comparison of manual versus computer-assisted radiographic measurement: intraobsever measurement variability for Cobb angles. Spine, v.23, n.5, p.551-555.

SKALLI, W.; LAVASTE, F.; DESCRIMES, J-L. (1995). Quantification of threedimensional vertebral rotations in scoliosis: What are the three values? Spine, v.20, n.5, p.546-553. 
SMITH, R. M. et al. (1991). The transverse plane deformity of strutural scoliosis. Spine, v.16, n.9, p.1126-1129.

SMITH, R. M.; DICKSON, R. A. (1987). Experimental strutural scoliosis. The Journal of Bone and Joint Surgery, v.69-B, n.4, p.576-581.

SMITH, T. J.; FERNIE, G. R. (1991). Functional biomechanics of the spine. Spine, v.16, n.10, p.1197-1203.

SOUCACOS, P. N. et al. (1997). School-screening for scoliosis: a prospective epidemiological study in northwestern and central Greece. The Journal of Bone and Joint Surgery, v.79-A, n.10, p.1498-1503.

SOUNIS, E. L. M. (1985). Bioestatística. 3. ed. São Paulo: Atheneu, 317p.

STOKES, I. A. F. (1989). Axial rotation component of thoracic scoliosis. Journal of Orthopaedic Research, v.7, n.5, p.702-708.

STOKES, I. A. F. (1991). Biomechanics testing and scoliosis: in vivo methods. Spine, v.16, n.10, p.1217-1223.

STOKES, I. A. F.; ARMSTRONG, J. G.; MORELAND.M. S. (1988). Spinal deformity and back surface asymetry in idipathic scoliosis. Journal of Orthopaedic Research, v.6, n.1, p.129-137.

STOKES, I. A. F.; BIGALOW, L. C.; MORELAND, M. S. (1986). Measurement of axial rotation of vertebrae in scoliosis. Spine, v.11, n.3, p.213-218.

STOKES, I. A. F.; BIGALOW, L. C.; MORELAND, M. S. (1987). Threedimensional spinal curvature in idiopathic scoliosis. Journal of Orthopaedic Research, v.5, n.1, p.102-113. 
STOKES, I. A. F.; DANSEREAU, J.; MORELAND, M. S. (1989). Rib cage asymmetry in idiophatic scoliosis. Journal of Orthopaedic Research, v.7, n.4, p.599-606.

STOKES, I. A. F.; GARDNER-MORSE, M. (1991). An analysis of the interation between vertebral lateral deviation and axial rotation in scoliosis. Journal of Biomechanics, v.24, n.8, p.753-759.

STOKES, I. A. F.; MORELAND, M. S. (1987). Measurement of the shape of the surface of the back in patients with scoliosis. The Journal of Bone and Joint Surgery, v.69-A, n.2, p.203-211.

STOKES, I. A. F.; MORELAND, M. S. (1989). Concordance of back surface asymmetry and spine shape in idiopathic scoliosis. Spine, v.14, n.1, p.73-78.

SURÓS, J. (1977). Semiologia médica y tecnica exploratoria. Barcelona: Salvat, p.949-968.

TERMINOLOGY committee of the scoliosis research society. (1976). A glossary of scoliosis terms. Spine, v.1, n.1, p.57-58.

THEOLOGIS, T. N. et al. (1993). Quantifying the cosmetic defect of adoslecent idiopathic scoliosis. Spine, v.18, n.7, p.909-912.

THEOLOGIS, T. N. et al. (1997). Early detection of progression in adolescent idiopathic scoliosis by measurement of changes in back with the Integrated Shape Imaging Systen Scanner. Spine, v.22, n.11, p.1223-1228.

THULBOURNE, T.; GILLESPIE, R. (1976). The rib hump in idiophatic scoliosis: measurement, analysis and response to treatment. The Journal of Bone and Joint Surgery, v.58-B, n.1, p.64-71. 
TURNER-SMITH, A.R. et al. (1988). A method for analysis of back shape in scoliosis. Biomechanics, v.21, n.6, p.497-509.

UNIVERSIDADE DE SÃO PAULO. Escola de Engenharia de São Carlos. Serviço de Biblioteca (1996). Diretrizes para elaboração de dissertações e teses na EESC-USP. 2 ed. São Carlos.

VERCAUTEREN,M. et al. (1982). Trunk asymmetries in a Belgian school population. Spine, v.7, n.6, p.555-562.

VINCHON, B. (1965). Présentation d'un appareil permettant la mesure des gibbosités scoliotiques. Revue de Chirurgie Orthopédique et Réparatrice de l' Appareil Moteur, v.51, n.7, p.643-644.

VIVIANI, G. et al. (1984). Assessment of accuracy of the scoliosis school screening examination. American Journal of Public Health, v.74, n.5, p.497498.

WEISS, H. R. (1995). Measurement of vertebral rotation: Perdriolle versus Raimondi. European Spine Journal, n.4, p.34-38.

WRIGHT, M.; FEINSTEIN, A. (1992). Improving the realiability of orthopaedic measurements. The Journal of Bone and Joint Surgery, v.74-B, n.2, p.287291.

XIONG, B. et al. (1995). Horizontal plane morphometry of normal and scoliotic vertebrae: A methodological study. European Spine Journal, v.4, p.6-10. 